Please do not remove this page

RMIT

UNIVERSITY

\title{
Airborne laser systems for atmospheric sounding in the near infrared
}

Sabatini, Roberto; Richardson, Mark; Jia, Huamin; Zammit-Mangion, David

https://researchrepository.rmit.edu.au/esploro/outputs/9921859449801341/filesAndLinks?institution=61 RMIT_INST\&index=null

Sabatini, R., Richardson, M., Jia, H., \& Zammit-Mangion, D. (2012). Airborne laser systems for atmospheric sounding in the near infrared. Proceedings of SPIE Vol. 8433, 1-40. https://doi.org/10.1117/12.915718 Document Version: Published Version

Published Version: https://doi.org/10.1117/12.915718

Repository homepage: https://researchrepository.rmit.edu.au

(C) 2012 SPIE

Downloaded On 2023/04/26 22:55:04 +1000

Please do not remove this page 
Thank you for downloading this document from the RMIT Research Repository.

The RMIT Research Repository is an open access database showcasing the research outputs of RMIT University researchers.

RMIT Research Repository: http://researchbank.rmit.edu.au/

\section{Citation:}

Sabatini, R, Richardson, M, Jia, H and Zammit-Mangion, D 2012, 'Airborne laser systems for atmospheric sounding in the near infrared', in Thomas Graf, Jacob I. Mackenzie, Helena Jelínková, John Powell (ed.) Proceedings of SPIE Vol. 8433, Brussels, Belgium, 16-19 April 2012, pp. 1-40.

See this record in the RMIT Research Repository at:

https://researchbank.rmit.edu.au/view/rmit:22754

Version: Published Version

\section{Copyright Statement:}

(C) 2012 SPIE

Link to Published Version:

http://dx.doi.org/10.1117/12.915718 


\section{Airborne laser systems for atmospheric sounding in the near infrared}

Roberto Sabatini, Mark A. Richardson, Huamin Jia, David Zammit-Mangion

Roberto Sabatini, Mark A. Richardson, Huamin Jia, David Zammit-Mangion, "Airborne laser systems for atmospheric sounding in the near infrared," Proc. SPIE 8433, Laser Sources and Applications, 843314 (11 May 2012); doi: 10.1117/12.915718 


\title{
Airborne Laser Systems for Atmospheric Sounding in the Near Infrared
}

\author{
Roberto Sabatini*a $^{\text {a }}$, Mark A. Richardson ${ }^{\mathrm{b}}$, Huamin Jia ${ }^{\mathrm{a}}$, David Zammit-Mangion ${ }^{\mathrm{a}}$ \\ ${ }^{a}$ Cranfield University - Department of Aerospace Engineering, Cranfield, Bedford MK43 0AL, UK \\ ${ }^{\mathrm{b}}$ Cranfield University - DAUK, Shrivenham, Swindon SN6 8LA, UK
}

\begin{abstract}
This paper presents new techniques for atmospheric sounding using Near Infrared (NIR) laser sources, direct detection electro-optics and passive infrared imaging systems. These techniques allow a direct determination of atmospheric extinction and, through the adoption of suitable inversion algorithms, the indirect measurement of some important natural and man-made atmospheric constituents, including Carbon Dioxide $\left(\mathrm{CO}_{2}\right)$. The proposed techniques are suitable for remote sensing missions performed by using aircraft, satellites, Unmanned Aerial Vehicles (UAV), parachute/gliding vehicles, Roving Surface Vehicles (RSV), or Permanent Surface Installations (PSI). The various techniques proposed offer relative advantages in different scenarios. All are based on measurements of the laser energy/power incident on target surfaces of known geometric and reflective characteristics, by means of infrared detectors and/or infrared cameras calibrated for radiance. Experimental results are presented relative to ground and flight trials performed with laser systems operating in the near infrared (NIR) at $\lambda=1064 \mathrm{~nm}$ and $\lambda=1550 \mathrm{~nm}$. This includes ground tests performed with $10 \mathrm{~Hz}$ and $20 \mathrm{KHz}$ PRF NIR laser systems in a variety of atmospheric conditions, and flight trials performed with a $10 \mathrm{~Hz}$ airborne NIR laser system installed on a TORNADO aircraft, flying up to altitudes of 22,000 ft above ground level. Future activities are planned to validate the atmospheric retrieval algorithms developed for $\mathrm{CO}_{2}$ column density measurements, with emphasis on aircraft related emissions at airports and other high air-traffic density environments.
\end{abstract}

Keywords: Airborne Lasers, Atmospheric Sounding, Carbon Dioxide, Green Aircraft Operations.

\section{INTRODUCTION}

In order to develop an understanding of the physics of our planet and to analyze the effects of human activities on climate change at a local and global level, it is fundamental to investigate atmospheric characteristics, with particular emphasis on spatial and temporal variability of the macroscopic observables as well as of the microphysical properties of the atmospheric constituents, including molecular species, aerosol particles and pollutants. Recent developments in the field of electro-optics have led to innovative sensors, systems, and analysis techniques for atmospheric remote sensing. The most widely used electro-optics techniques for Earth atmospheric sounding are passive visible-infrared imaging and active LIDAR (Light Detection and Ranging) volume scattering, both from satellite and airborne platforms. Both techniques allow accurate measurements of atmospheric components (molecules and aerosol species). However, imaging measurements have the disadvantage of being limited in accuracy, especially if compared with electro-optics direct and coherent detection techniques. Furthermore, some effects, like the influence of turbulence structure constant variations, are difficult to model using these techniques, and any mathematical extrapolation or empiric estimation would add a considerable amount of uncertainty to the measurements performed. On the other hand, LIDAR measurements are more accurate but often limited to shorter ranges than those provided by imaging sensors. This is particularly through if we consider the characteristics of the Earth's atmosphere, where high concentrations of carbon dioxide $\left(\mathrm{CO}_{2}\right)$, oxygen $\left(\mathrm{O}_{2}\right)$, nitrogen $(\mathrm{N})$, water and aerosol/particulate species determine a large variety of absorption and scattering processes. Furthermore, atmospheric turbulence also contribute to significant laser energy fluctuations on the focal plane, and various nonlinear propagation effects, such as bleaching and thermal blooming, may also cause severe attenuations of laser beams propagating in the atmosphere [1-9].

*r.sabatini@ cranfield.ac.uk; phone +44 (0)1234 758290; fax +44 (0)1234 758203; www.cranfield.ac.uk

Laser Sources and Applications, edited by Thomas Graf, Jacob I. Mackenzie, Helena Jelínková, John Powell, Proc. of SPIE Vol. 8433, 843314 · @ 2012 SPIE · CCC code: 0277-786X/12/\$18 · doi: 10.1117/12.915718 
The advent of powerful laser sources and pointing systems, with low weight and packaged in relatively small casings, allows for different laser sources to be installed on aircraft, satellites or other aerial/surface vehicles. Additionally, due the advent of powerful tunable laser sources, a variety of LIDAR systems have been developed for measuring the concentration/column density of various important molecular species, including Carbon Oxides $\left(\mathrm{CO}_{\mathrm{x}}\right), \mathrm{NO}_{\mathrm{x}}$, Oxigen $\left(\mathrm{O}_{2}\right)$ and Ozone $\left(\mathrm{O}_{3}\right)$, both locally and over extended geographic areas [10-12]. The propagation characteristics of NearInfrared (NIR) lasers make them particularly well suited for $\mathrm{CO}$ and $\mathrm{CO}_{2}$ density measurements. In this region of the spectrum propagation is dominated by molecular absorption from $\mathrm{H}_{2} \mathrm{O}, \mathrm{CO}$ and $\mathrm{CO}_{2}$. Therefore, comparison to recorded $\mathrm{H}_{2} \mathrm{O}$ spectra enables the identification of relatively strong and isolated $\mathrm{CO}$ and $\mathrm{CO}_{2}$ transitions for unambiguous species detection. These transitions have formed the basis of NIR sensors for measurements of $\mathrm{CO}$ and $\mathrm{CO}_{2}$ mole fractions in exhaust gases using extraction-sampling techniques and for non-intrusive measurements of $\mathrm{CO}_{2}$ in high-temperature combustion environments. Currently, great attention is being devoted to airborne and spaceborne laser sensors for $\mathrm{CO}_{2}$ column density measurements [13]. Typical applications include global warming and environmental studies, with manmade $\mathrm{CO}_{2}$ emissions being major considerations in such work. In the aviation domain, there is a growing interest in $\mathrm{CO}_{2}$ measurements at airports and their environs, as well as in other high-density air traffic areas. Although air transport is currently responsible for only $2 \%$ of the overall man-made carbon dioxide emissions, the global community is working to reduce the level of emissions as growth in air transport is forecast to increase such emissions by $50 \%$ over current levels by 2050. In this respect, Clean Sky, a Joint Technology Initiative, a $€ 1.6$ billion program part-funded by the European Commission, is aimed at reducing the impact of air transport on the environment in a holistic manner. Amongst other aspects, Clean Sky aims to reduce $\mathrm{CO}_{2}$ emissions through the design of more efficient engines and airframes and through better utilization of aircraft (which involves flying more efficient trajectories). An area Clean Sky is addressing, and one to which the aviation community and society is sensitive to, is the level of emissions and pollution at airports and terminal areas, particularly at large hubs. Legislation is already in place with respect to noise pollution and noise measuring equipment is being used to measure noise levels. Given the growing political pressures, it is expected that such initiatives will be extended to $\mathrm{CO}_{2}$ emissions, where airports and other high aircraft density areas would be monitored for the overall emissions in the environment. In this scenario, our main goal is to establish the feasibility of a new robust and inexpensive technique that will permit measurements of the $\mathrm{CO}_{2}$ and other atmospheric gases/particle concentration in the atmosphere from aircraft and ground installations, with a capability of scaling to permit global measurements from satellites as well. Accurate remote sensing measurements of $\mathrm{CO}_{2}$ mixing ratios from aircraft and space are difficult. Potential error sources include possible interferences from other trace gas species, the effects of clouds and aerosols in the path, and variability in dry air density caused by pressure or topographic changes. In existing LIDAR systems used to determine $\mathrm{CO}_{2}$ column density, the required transmittance measurements at different (contiguous) wavelengths are typically performed using LIDAR systems with tunable lasers producing output at the required wavelengths. Previous researchers, such as Krainak et al. [14], have reported LIDAR measurements using several different $\mathrm{CO}_{2}$ lines in the $1570 \mathrm{~nm} \mathrm{CO}$ absorption band with direct detection receivers. Particularly, integrated path $\mathrm{CO}_{2}$ absorption measurements were performed over a 200-m horizontal path to a reflective target, using a tunable LIDAR system consisting of a wavelength scanned diode laser followed by Erbium-doped fibre amplifier, which repeatedly swept across the $1572.33 \mathrm{~nm}$ line. In this experiment, the direct detection receiver used a PIN photodiode detector. Riris et al. [15] and Allan et al. [16] also described the evolution of this LIDAR, its use for longer duration $\mathrm{CO}_{2}$ absorption measurements over 0.4 and $1.6 \mathrm{~km}$ long horizontal paths, and comparison of its measurements with in situ sensor readings. In order to avoid the drawbacks of tuning the laser source to different frequencies (e.g., reduced output power and range), various researchers have also investigated multiple collocated laser sources pointing in the same direction. In all previously proposed LIDAR systems, potential instrumental errors include frequency drifts in the transmitter and sensitivity drifts in the receiver. In traditional LIDAR systems, a priori estimates of the surface IR radiation and reflection characteristics are needed (terrain, water, etc.). For accurate measurements of $\mathrm{CO}_{\mathrm{x}}$ species concentrations (down to a few ppm) NIR tunable LIDARs have been used in previous research and the key observable in this case is the transmittance in-and-out of specific absorption lines. Because of these factors and due to the double path transmission needed in LIDAR, long-range and accurate atmospheric gas retrieval requires very high power and Signalto-Noise Ratio (SNR), which are difficult to achieve with commercially available tunable NIR lasers. Therefore, we envisage the opportunity of applying our single-path transmittance measurement techniques to the problem of long-range airborne and spaceborne $\mathrm{CO}_{2}$ column density analysis. 


\section{LASER BEAM PROPAGATION OVERVIEW}

Several research activities have been undertaken for characterizing and modelling linear and non-linear atmospheric propagation effects on laser beams. In the following paragraphs, only a brief introduction to the fundamentals of laser beam propagation is presented, with emphasis on those phenomena affecting the peak irradiance at a distant location from the laser output aperture.

\subsection{Atmospheric Transmittance}

Attenuation of laser radiation in the atmosphere is described by Beer's law [1]:

$$
\tau_{\text {atm }}=\frac{I(z)}{I_{0}}=e^{-\gamma z}
$$

where $\tau_{\text {atm }}$ is the transmittance, $\gamma$ is the attenuation coefficient (extinction), and $z$ is the length of the transmission path. Since the attenuation coefficient is a function of the molecular and aerosol particle concentrations along the path, Eq. (1) becomes:

$$
\tau_{\text {atm }}=e^{-\int_{0}^{z} \gamma(z) d z}
$$

were the attenuation coefficient is determined by four individual processes: molecular absorption, molecular scattering, aerosol absorption, and aerosol scattering. Therefore:

$$
\gamma=\alpha_{m}+\beta_{m}+\alpha_{a}+\beta_{a}
$$

where $\alpha$ is the absorption coefficient, $\beta$ is the scattering coefficient, and the subscripts $m$ and $a$ designate the molecular and aerosol processes, respectively. Each coefficient in Eq. (3) depends on the wavelength of the laser radiation. We find it convenient at times to discuss absorption and scattering in terms of the absorption and scattering cross sections $\left(\sigma_{a}\right.$ and $\sigma_{s}$, respectively) of the individual particles that are involved. Therefore, we can write:

$$
\alpha=\sigma_{a} N_{a}
$$

and

$$
\beta=\sigma_{s} N_{s}
$$

where $N_{a}$ and $N_{s}$ are the concentrations of the absorbing and scattering species respectively. In the absence of precipitation, the Earth's atmosphere contains finely dispersed solid and liquid particles (of ice, dust, aromatic and organic material) that vary in size from a cluster of a few molecules to particles of about $20 \mu \mathrm{m}$ in radius. Particles larger than this remain airborne for a short time and are only found close to their sources. Such a colloidal system, in which a gas (in this case, air) is the continuous medium and particles of solid or liquid are dispersed, is known as an aerosol. Aerosol attenuation coefficients depend considerably on the dimensions, chemical composition, and ncentration of aerosol particles. These particles are generally assumed to be homogeneous spheres that are characterized by two parameters: the radius and the index of refraction. In general, the index of refraction is complex. Therefore, we can write:

$$
\tilde{n}=n-i k=n\left(1-i \frac{k}{n}\right)=n(1-i \kappa)
$$

where $n$ and $k$ are the real and imaginary parts and $\kappa=k / n$ is known as the extinction coefficient. In general, both $n$ and $k$ are functions of the frequency of the incident radiation. The imaginary part (which arises from a finite conductivity of the particle) is a measure of the absorption. In fact, $k$ is referred to as the absorption constant. It is related to the absorption coefficient $\alpha$ of Eqs. (3) and (4) by:

$$
\alpha=\frac{4 \pi f k}{c}
$$

where $c$ is the speed of light in a vacuum and $f$ is the frequency of the incident radiation. The scattering coefficient $\beta$ in Eqs. (3) and (5) also depends on the frequency of the incident radiation as well as the index of refraction and radius of 
the scattering particle. The incident electromagnetic wave, which is assumed to be a plane wave in a given polarization state, produces forced oscillations of the bound and free charges within the sphere. These oscillating charges in turn produce secondary fields internal and external to the sphere. The resulting field at any point is the vector sum of the primary (plane wave) and secondary fields. Once the resultant field has been determined, the scattering cross section $\left(\sigma_{s}\right)$ is obtained from the following relationship:

$$
\sigma_{s}=\frac{P_{s}}{|M|_{T}}
$$

where $P_{s}$ is the total power scattered by scatterer, and $|M|_{T}$ is the time-averaged incident Poynting vector. In the scattering process there is no loss of energy but only a directional redistribution which may lead to a significant reduction in beam intensity for large path lengths. As is indicated in Table 1, the physical size of the scatterer determines the type of scattering process. Thus, air molecules which are typically several angstrom units in diameter lead to Rayleigh scattering, whereas the aerosols scatter light in accordance with the Mie theory. Furthermore, when the scatterers are relatively large, such as the water droplets found in fog, clouds, rain, or snow, the scattering process is more properly described by diffraction theory.

The atmospheric composition of Earth is largely governed by the by-products of the life that it sustains. Earth's atmosphere consists principally of a roughly 78:20 ratio of nitrogen $\left(\mathrm{N}_{2}\right)$ and oxygen $\left(\mathrm{O}_{2}\right)$, plus substantial water vapor, with a minor proportion of carbon dioxide $\left(\mathrm{CO}_{2}\right)$. Due to human activities, the $\mathrm{CO}_{2}$ concentartions are constantly growing (this has been recognized as a main contributing factor to climate change and global warming). There are also smaller concentrations of hydrogen, and of helium, argon, and other noble gases. Volatile pollutants, including various types of man-made gases and aerosols with largely variable particle size distributions are also present. For the wavelength range of greater interest in laser beam propagation (the visible region to about $15 \mu \mathrm{m}$ ) the principal atmospheric absorbers are the molecules of water, $\mathrm{CO}_{2}$ and ozone. Attenuation occurs because these molecules selectively absorb radiation by changing vibration and rotation energy states. The two gases present in greatest abundance in the Earth's atmosphere, nitrogen and oxygen, are homonuclear, which means that they possess no electric dipole moment and therefore do not exhibit molecular absorption bands. The Earth's atmospheric spectral transmittance $\tau_{(\%)}$ measured over a 1820-m horizontal path at sea-level is shown in Fig. 1.

Table 1. Types of atmospheric scattering.

\begin{tabular}{||l|l||}
\hline Type of Scattering & Size of Scatterer \\
\hline \hline Rayleigh Scattering & Larger than electron but smaller than $\lambda$ \\
\hline Mie Scattering & Comparable in size to $\lambda$ \\
\hline Non-selective Scattering & Much larger than $\lambda$ \\
\hline
\end{tabular}




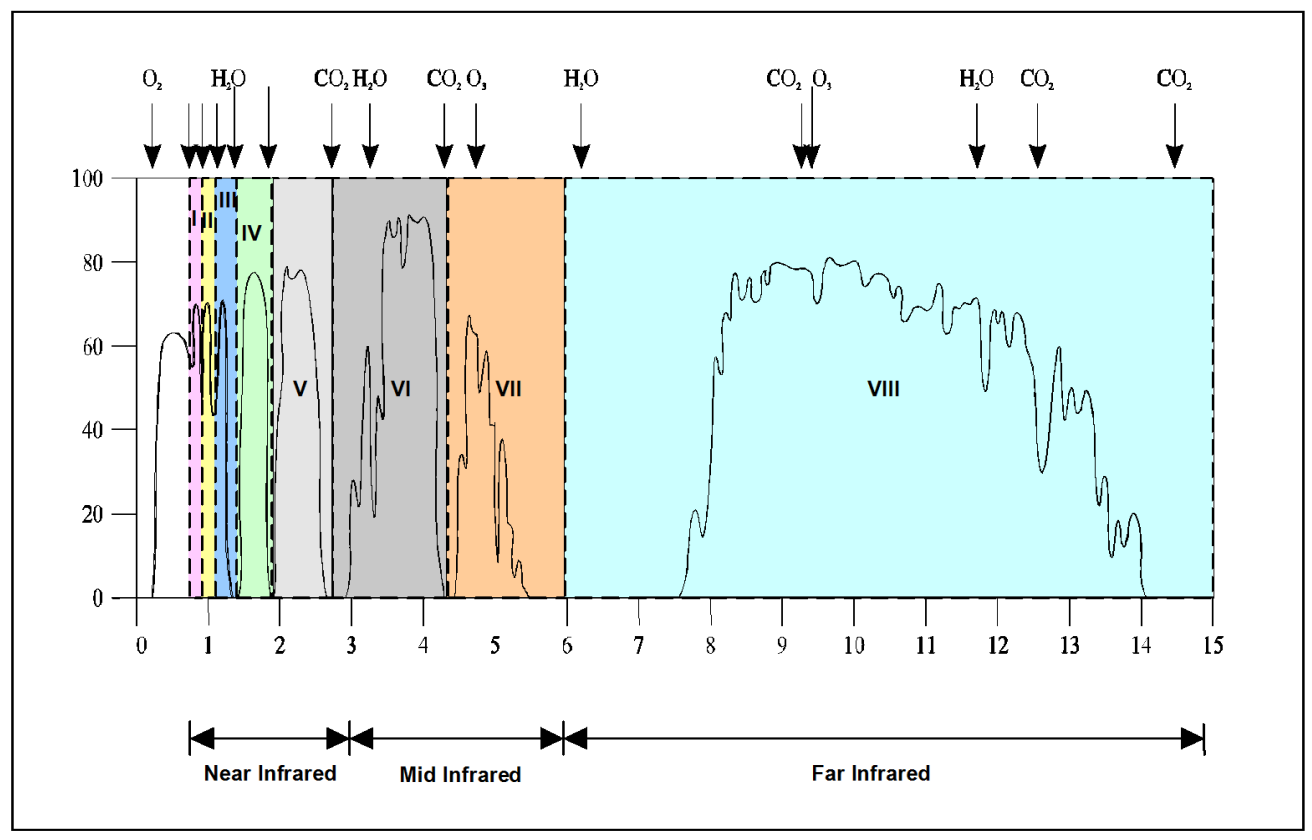

Figure 1. Sea-level transmittance over a $1820 \mathrm{~m}$ horizontal path [2].

The molecule responsible for each absorption band is shown in the upper part of the figure. It is evident that $\mathrm{H}_{2} \mathrm{O}$ and $\mathrm{CO}_{2}$ are by far the most important absorbing molecules. This is also the case for the range of altitudes extending from sea level to about $12 \mathrm{~km}$. Depending on weather conditions, altitude, and geographical location, the concentration of $\mathrm{H}_{2} \mathrm{O}$ varies between $10^{-3}$ and 1 percent (by volume). Normally, the concentration of $\mathrm{CO}_{2}$ varies between 0.03 and 0.04 percent. However, the concentration of $\mathrm{CO}_{2}$ at a local level can reach much higher values due to human activities. Other absorbing molecules found in the atmosphere are methane $\left(\mathrm{CH}_{4}\right)$, with a concentration of around $1.5 \times 10^{-4}$ percent; nitrous oxide $\left(\mathrm{N}_{2} \mathrm{O}\right)$, with a concentration of around $3.5 \times 10^{-5}$ percent; carbon monoxide $(\mathrm{CO})$ with a typical concentration of $2 \times 10^{-5}$ percent; and ozone $\left(\mathrm{O}_{3}\right)$, with a concentration as large as $10^{-3}$ percent at an altitude of around 30 $\mathrm{km}$. The concentration of ozone near sea level is negligible. In Fig. 2 the wavelength intervals where the transmittance is relatively high are called "atmospheric windows". Obviously, for efficient energy transmission the laser wavelength should fall well within one of these windows. There are a total of eight such windows within the wavelength range from 0.72 to $15.0 \mu \mathrm{m}$. The window boundaries are listed in Table 2 .

Table 2. Wavelength regions of Earth's atmospheric windows.

\begin{tabular}{||c|cc||}
\hline Window Number & \multicolumn{2}{|c|}{ Window Boundaries $(\boldsymbol{\mu m})$} \\
\hline \hline I & 0.72 & 0.94 \\
\hline II & 0.94 & 1.13 \\
\hline III & 1.13 & 1.38 \\
\hline IV & 1.38 & 1.90 \\
\hline V & 1.90 & 2.70 \\
\hline VI & 2.70 & 4.30 \\
\hline VII & 4.30 & 6.00 \\
\hline VIII & 6.00 & 15.0 \\
\hline
\end{tabular}


When we consider molecular absorption only, the fraction of monochromatic radiation transmitted (i.e., the transmittance) is given by:

$$
\tau(f)=e^{-\alpha(f) z}
$$

were $\alpha(f)$ is the frequency-dependent absorption coefficient and $z$ is the path length. Eq. (9) is valid when the absorption coefficient is constant for the entire path length $z$. To describe slant path propagation where $\alpha(f)$ is not a constant over the path length, one uses the more general expression:

$$
\tau(f)=\exp \left[-\int_{0}^{l} \sigma_{a}(f) N d r\right]
$$

where $\sigma_{a}(f)$ is the absorption cross section, $N$ is the number density of absorbing molecules, and the integration extends over the propagation range of length $l$.

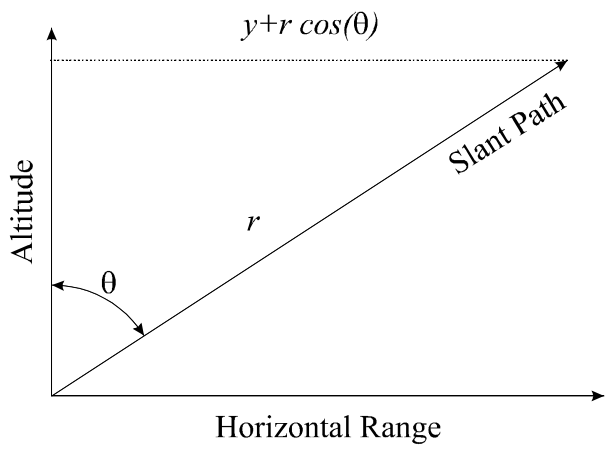

Figure 2. Geometry of laser beam propagating along slant path.

The transmittance of the atmosphere for a laser beam propagating along the slant path shown in Fig. 2 is then given by:

$$
\tau(f)=\exp \left[-\sec (\theta) \int_{0}^{y+r \cdot \cos (\theta)} N(y) \sigma_{a}(f, y) d y\right]
$$

The ideal gas law may be used to express the integrand in Eq. (C.3) in terms of the atmospheric pressure $p(y)$ at the altitude $y$ and the fractional concentration $f(y)$. Thus, we have:

$$
N(y)=f(y) p(y) / k T(y)
$$

For an isothermal atmosphere and assuming that air is an ideal gas, the pressure as a function of the altitude can be shown to be given by the following expression:

$$
p(y)=p_{0} e^{-y / H}
$$

where $H=k T / m g$ is customarily referred to as the scale height. The parameters $m=\left(\Sigma_{j} m_{j} N_{j}\right) / N$ and $g$ are the average molecular mass and gravitational acceleration, respectively. The scale height is the distance in which the pressure of an isothermal atmosphere of constant composition drops by a factor of $e^{-1}$. Eq. (12) does not apply to the ozone and water vapour concentrations. The amount of ozone is chiefly a function of the altitude only, while the amount of water vapour depends on the relative humidity. If we next assume that the absorption cross section $\sigma_{a}(f)$ has a Lorentz line shape of line width $\Delta f$ (i.e., collisions are the dominant line-broadening mechanism), then:

$$
\Delta f=\Delta f_{0}\left(\frac{p(y)}{p_{0}}\right)^{\sqrt{\frac{T_{0}}{T(y)}}}
$$


The subscript $O$ refers to a reference altitude. Because of the more numerous collisions of the absorbing molecules with $\mathrm{N}_{2}$ and $\mathrm{O}_{2}$ molecules, the broadening pressure in Eq. (14) is simply the total atmospheric pressure at the altitude of interest. The absorption cross section as a function of frequency and altitude may be expressed in the form:

$$
\sigma_{a}(f, y)=\frac{S(y) \Delta f(y)}{2 \pi\left[\left(f-f_{0}\right)^{2}+\left(\frac{\Delta f(y)}{2}\right)^{2}\right]}
$$

The parameter $S(y)$ is called the line intensity or line strength and is given by:

$$
S(y)=\int_{-\infty}^{\infty} \sigma_{a}(f, y) d f
$$

The total molecular absorption coefficient at the laser frequency $f$ is found by summing over each molecular species present and the various allowed transitions that contribute to the total absorption coefficient. Therefore, we have:

$$
\alpha(f)=\sum_{i} \sum_{j} \frac{S_{i j}(y) \Delta f_{i j}(y) N_{j}(y)}{2 \pi\left[\left(f-f_{0, i j}\right)^{2}+\left(\frac{\Delta f_{i j}(y)}{2}\right)^{2}\right]}
$$

The subscript $i$ refers to the $i^{\text {th }}$ line of the $j^{\text {th }}$ molecular species with the number density $N_{j}(y)$. For example, a He-Ne laser typically can be operated at $0.6328 \mu \mathrm{m}$ or at $1.152276 \mu \mathrm{m} . \mathrm{H}_{2} \mathrm{O}$ molecules have five absorption lines in proximity of the second wavelength. These absorption lines are centred at $1.152277 \mu \mathrm{m}, 1.152319 \mu \mathrm{m}, 1.152373 \mu \mathrm{m}, 1.152420$ $\mu \mathrm{m}$ and $1.152423 \mu \mathrm{m}$ and, as a consequence, the total absorption is due to the sum of the contributions from each line. This example shows another important aspect of the interaction of laser radiation with the atmosphere. Since the line widths of lasers are typically very narrow (e.g., between $10^{-3}$ and about $2 \AA$ for gas lasers), the spectral absorption regions of interest are also very narrow. Experimentally this necessitates high resolution measurements and the usual tables or spectral transmittance curves, which give average absorption over relatively wide bands, are not immediately applicable to laser beam absorption. Combining Eqs. (11) and (18), the atmospheric transmittance at the frequency $f$ is given by:

$$
\tau(f)=\exp \left\{-\frac{\sec (\theta)}{2 \pi} \int_{0}^{y+r \cos (\theta)} \sum_{i} \sum_{j} \frac{S_{i j}(y) \Delta f_{i j}(y) N_{j}(y)}{2 \pi\left[\left(f-f_{0, i j}\right)^{2}+\left(\frac{\Delta f_{i j}(y)}{2}\right)^{2}\right]} d y\right\}
$$

This equation must be evaluated by analytic or numerical techniques. Obviously, any exact evaluation of Eq. (18) is exceedingly difficult. Most calculations of this sort assume a model standard clear atmosphere and require estimates that are at times not much better than educated guesses. As a consequence, experimental measurements are required. Fortunately, a large amount of high-resolution data is now available, together with high-resolution transmission codes.

In addition to molecular absorption by discrete absorption lines, there exists a slowly varying component of molecular absorption in the atmosphere caused mainly by molecular clusters. This absorption plays a fundamental role particularly in "window" regions where absorption by discrete lines is small. It is difficult to separate the cluster molecular absorption from absorption in the distant wings of strong discrete absorption lines. For practical reasons far wing absorption and cluster absorption are combined and called "continuum" absorption. In regions of more substantial line absorption, the problem reduces to that of deciding how far into the wings of each line to assume individual line contributions and how much of the experimentally observed absorption to model as "continuum". Various models have been developed for continuum absorption contributions in the various atmospheric windows [2]. However, it should be underlined that, because of the considerable lack of experimental data and the physical complexity of continuum absorption processes, there is still some uncertainty in the continuum contributions. 


\subsection{Transmittance Calculation Tools and Practical Models}

In principle, one could determine the exact composition of the atmosphere over the path of interest and, employing the physics of molecular and aerosol extinction, compute the atmospheric extinction coefficient. Because of the wide variations in weather conditions and sparsity of data on some atmospheric constituents, it is desirable to adopt an engineering approach to atmospheric modelling. The required model must include several weather conditions and shall be validated with laboratory and field data. To deal with these complex phenomena, the Phillips Laboartory of the Geophysics Directorate at Hanscom Air Force Base (Massachusetts) has developed codes to predict transmittance/radiance effects for varying conditions. Particularly, they have progressively developed software tools

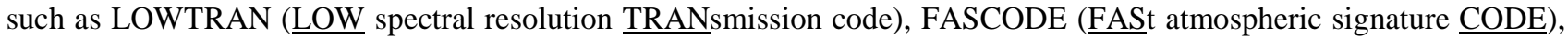
MODTRAN (MODerate spectral resolution TRANsmission code), and HITRAN (HIgh resolution TRANsmission code). Furthermore, in recent years, powerful tools for the assessment and exploitation of propagation conditions together with range performance models for military systems have become available. It is impossible to present in comprehensive way all available tools. Instead, in the following we present some empirical models selected for our practical applications are discussed. Particularly, we focus on models providing sufficiently accurate data in terms of absorptive and scattering transmittance, using the meteorological data typically available in an airport environment.

An empirical approach yielding approximate values of the absorption coefficient, has been suggested by Elder and Strong [3] and modified by Langer [4]. Their approach is particularly useful because it provides a means of relating the atmospheric transmission of the $i^{\text {th }}$ window to the relative humidity (i.e., a readily measurable parameter). The assumption is that variations in the transmission are caused by changes in the water content of the air. Specifically, changes in the concentration of $\mathrm{H}_{2} \mathrm{O}$ cause changes in the absorption, and changes in the size and number of water droplets with humidity cause changes in the scattered component. This is a valid assumption since the other atmospheric constituents have a reasonably constant effect on the transmittance of a given atmospheric window.

It is customary to express the number of $\mathrm{H}_{2} \mathrm{O}$ molecules encountered by the beam of light in terms of the number of precipitable millimetres of water in the path. Specifically, the depth of the layer of water that would be formed if all the water molecules along the propagation path were condensed in a container having the same cross-sectional area as the beam is the amount of precipitable water. A cubic meter of air having an absolute humidity of $\rho$ grams per $\mathrm{m}^{3}$ would yield condensed water that cover a $1 \mathrm{~m}^{2}$ area and have a depth of:

$$
w^{\prime}=10^{-3} \rho
$$

$w^{\prime}$ is the precipitable water having units of mm per meter of path length. For a path length of $z$ meters Eq. (19) becomes:

$$
w=10^{-3} \rho \cdot z
$$

where $w$ is now the total precipitable water in millimetres. The value of $\rho$, the density of water vapour, can be found by multiplying the appropriate number in Table 3-3 by the relative humidity $(R H)$.

\begin{tabular}{|c|c|c|c|c|c|c|c|c|c|c|}
\hline \multicolumn{11}{|c|}{ Temperature } \\
\hline$\left({ }^{\circ} \mathrm{C}\right)$ & 0 & 1 & 2 & 3 & 4 & 5 & 6 & 7 & 8 & 9 \\
\hline-20 & 0.89 & 0.81 & 0.74 & 0.67 & 0.61 & 0.65 & & & & \\
\hline-10 & 2.15 & 1.98 & 1.81 & 1.66 & 1.52 & 1.40 & 1.28 & 1.18 & 1.08 & 0.98 \\
\hline-0 & 4.84 & 4.47 & 4.13 & 3.81 & 3.52 & 3.24 & 2.99 & 2.75 & 2.54 & 2.34 \\
\hline 0 & 4.84 & 5.18 & 5.54 & 5.92 & 6.33 & 6.76 & 7.22 & 7.70 & 8.22 & 8.76 \\
\hline 10 & 9.33 & 9.94 & 10.57 & 11.25 & 11.96 & 12.71 & 13.50 & 14.34 & 15.22 & 16.17 \\
\hline 20 & 17.22 & 18.14 & 19.22 & 20.36 & 21.55 & 22.80 & 24.11 & 25.49 & 27.00 & 28.45 \\
\hline 30 & 30.04 & 31.70 & 33.45 & 35.28 & 37.19 & 39.19 & & & & \\
\hline
\end{tabular}

Table 3. Mass of water vapour in saturated air $(\mathrm{g} / \mathrm{m} 3)$. 
Similar numerical results can be obtained using the following equation [6], which is convenient for computer code implementation:

$$
\rho=1322.8 \cdot \frac{R H}{T} \exp \left[\frac{25.22 \cdot(T-273.16)}{T}-5.31 \cdot \ln \left(\frac{T}{273.16}\right)\right]
$$

where $R H$ is the relative humidity (as a fraction), and $T$ is the absolute temperature $\left({ }^{\circ} \mathrm{K}\right)$. Based on the work done by Elder and Strong [3], two empirical expressions, developed by Langer [4], can be used to calculate the absorptive transmittance $\tau_{a i}$ for the $i^{\text {th }}$ window for any given value of the precipitable water content. These expressions are:

$$
\begin{gathered}
\tau_{a i}=e^{-A_{i} \sqrt{w}}, \text { for } w<w_{i} \\
\tau_{a i}=k_{i}\left(\frac{w_{i}}{w}\right)^{\beta_{i}}, \text { for } w>w_{i}
\end{gathered}
$$

\begin{tabular}{|c|c|c|c|c|}
\hline Window & $A_{i}$ & $k_{i}$ & $\beta_{i}$ & $w_{i}$ \\
\hline I & 0.0305 & 0.800 & 0.112 & 54 \\
\hline II & 0.0363 & 0.765 & 0.134 & 54 \\
\hline III & 0.1303 & 0.830 & 0.093 & 2.0 \\
\hline IV & 0.211 & 0.802 & 0.111 & 1.1 \\
\hline $\mathbf{V}$ & 0.350 & 0.814 & 0.1035 & 0.35 \\
\hline VI & 0.373 & 0.827 & 0.095 & 0.26 \\
\hline VII & 0.598 & 0.784 & 0.122 & 0.165 \\
\hline
\end{tabular}

where $A_{i}, k_{i}, \beta_{i}$ and $w_{i}$ are constants whose values for each atmospheric window are listed in Table 4.

Table 4. Constants to be used in Eqs. (3.34) and (3.35).

In summary, Eqs. (22) and (23), together with Eq. (20) and Table 3 (or Eq. 21), provide information that can be used to obtain an estimate of the absorptive transmittance $\left(\tau_{a i}\right)$ of laser beams having wavelengths that fall within the various atmospheric windows. The results apply to horizontal paths in the atmosphere near sea-level and for varying relative humidity. To obtain the total atmospheric transmittance we must multiply $\tau_{a i}$ by $\tau_{s i}$ (i.e., the transmittance due to scattering only).

Based on rigorous mathematical approaches, the scattering properties of the atmosphere due to the aerosol particles are difficult to quantify, and it is difficult to obtain an analytic expression for the scattering coefficient that will yield accurate values over a wide variety of conditions. However, an empirical relationship that is often used to model the scattering coefficient [5] has the form:

$$
\beta(\lambda)=C_{1} \lambda^{-\delta}+C_{2} \lambda^{-4}
$$

where $C_{1}, C_{2}$, and $\delta$ are constants determined by the aerosol concentration and size distribution, and $\lambda$ is the wavelength of the radiation. The second term accounts for Rayleigh scattering. Since for all wavelengths longer than about $0.3 \mu \mathrm{m}$ the second term is considerably less than the first, it may be neglected. It has been found that $\delta \approx 1.3 \pm 0.3$ produces reasonable results when applied to aerosols with a range of particle sizes. 
An attempt has also been made to relate $\delta$ and $C_{l}$ to the meteorological range. The apparent contrast $C_{z}$, of a source when viewed at $\lambda=0.55 \mu \mathrm{m}$ from a distance $z$ is by definition:

$$
C_{z}=\frac{R_{s z}-R_{b z}}{R_{b z}}
$$

where $R_{s z}$ and $R_{b z}$ are the apparent radiances of the source and its background as seen from a distance $z$.

For $\lambda=0.55 \mu \mathrm{m}$, the distance at which the ratio:

$$
V=\frac{C_{z}}{C_{0}}=\frac{\frac{R_{s z}-R_{b z}}{R_{b z}}}{\frac{R_{s 0}-R_{b 0}}{R_{b 0}}}=0.02
$$

is defined as the meteorological range $V$ (or visual range). It must be observed that this quantity is different from the standard observer visibility $\left(V_{\text {obs }}\right)$. Observer visibility is the greatest distance at which it is just possible to see and identify a target with the unaided eye. In daytime, the object used for $V_{o b s}$ measurements is dark against the horizon sky (e.g., high contrast target), while during night time the target is a moderately intense light source. The International Visibility Code (IVC) is given in Table 5. It is evident that, while the range of values for each category is appropriate for general purposes, it is too broad for scientific applications.

Table 5. International Visibility Code (IVC).

\begin{tabular}{||c|c||}
\hline Designation & Visibility \\
\hline \hline Dense Fog & $0-50 \mathrm{~m}$ \\
\hline Thick Fog & $50-200 \mathrm{~m}$ \\
\hline Moderate Fog & $200-500 \mathrm{~m}$ \\
\hline Light Fog & $500-1 \mathrm{~km}$ \\
\hline Thin Fog & $1-2 \mathrm{~km}$ \\
\hline Haze & $2-4 \mathrm{~km}$ \\
\hline Light Haze & $4-10 \mathrm{~km}$ \\
\hline Clear & $10-20 \mathrm{~km}$ \\
\hline Very Clear & $20-50 \mathrm{~km}$ \\
\hline Exceptionally Clear & $>50 \mathrm{~km}$ \\
\hline \hline
\end{tabular}

Visibility is a subjective measurement estimated by a trained observer and as such can have large variability associated with the reported value. Variations are created by observers having different threshold contrasts looking at nonideal targets. Obviously, visibility depends on the aerosol distribution and it is very sensitive to the local meteorological conditions. It is also dependent upon the view angle with respect to the sun. As the sun angle approaches the view angle, forward scattering into the line-of-sight increases and the visibility decreases. Therefore, reports from local weather stations may or may not represent the actual conditions at which the experiment is taking place. Since meteorogical range is defined quantitatively using the apparent contrast of a source (or the apparent radiances of the source and its background) as seen from a certain distance, it eliminates the subjective nature of the observer and the distinction between day and night. Unfortunately, carelessness has often resulted in using the term "visibility" when meteorological range is meant. To insure that there is no confusion, "observer-visibility" $\left(V_{o b s}\right)$ will be used in this thesis to indicate that it is an estimate. 
If only $V_{o b s}$ is available, the meteorological range $(V)$ can be estimated [6] from:

$$
V \approx(1.3 \pm 0.3) \cdot V_{o b s}
$$

From Eq. (26), if we assume that the source radiance is much greater than the background radiance (i.e., $R_{s}>>R_{b}$ ) and that the background radiance is constant (i.e., $R_{b o}=R_{b z}$ ), then the transmittance at $\lambda=0.55 \mu \mathrm{m}$ (where absorption is negligible) is given by:

$$
\frac{R_{s v}}{R_{s 0}}=e^{-\beta V}=0.02
$$

Hence, we have:

$$
\ln \left(\frac{R_{s v}}{R_{s 0}}\right)=-\beta V=-3.91
$$

and also:

$$
\beta=\frac{3.91}{V}=C_{1} \lambda^{-\delta}
$$

It follows from Eq. (29) that the constant $C_{l}$ is given by:

$$
C_{1}=\frac{3.91}{V} \cdot 0.55^{\delta}
$$

With this result the transmittance at the centre of the $i^{\text {th }}$ window is:

$$
\tau_{s i}=e^{-\frac{3.91}{V} \cdot\left(\frac{\lambda_{i}}{0.55}\right)^{-\delta} \cdot z}
$$

where $\lambda_{i}$ must be expressed in microns. If, because of haze, the meteorological range is less than $6 \mathrm{~km}$, the exponent $\delta$ is related to the meteorological range by the following empirical formula:

$$
\delta=0.585 \sqrt[3]{V}
$$

where $V$ is in kilometres. When $V \geq 6 \mathrm{~km}$, the exponent $\delta$ can be calculated by:

$$
\delta=0.0057 \cdot V+1.025
$$

For exceptionally good visibility $\delta=1.6$, and for average visibility $\delta \approx 1.3$. In summary, Eq. (32), together with the appropriate value for $\delta$, allows to compute the scattering transmittance at the centre of the ith window for any propagation path, if the meteorological range $V$ is known. It is important to note here that in general the transmittance will, of course, also be affected by atmospheric absorption, which depending on the relative humidity and temperature may be larger than $\tau_{\text {si. }}$

\subsection{Propagation Through Haze and Precipitation}

Haze refers to the small particles suspended in the air. These particles consist of microscopic salt crystals, very fine dust, and combustion products. Their radii are less than $0.5 \mu \mathrm{m}$. During periods of high humidity, water molecules condense onto these particles, which then increase in size. It is essential that these condensation nuclei be available before condensation can take place. Since salt is quite hygroscopic, it is by far the most important condensation nucleus. Fog occurs when the condensation nuclei grow into water droplets or ice crystals with radii exceeding $0.5 \mu \mathrm{m}$. Clouds are formed in the same way; the only distinction between fog and clouds is that one touches the ground while the other does not. By convention fog limits the visibility to less than $1 \mathrm{~km}$, whereas in a mist the visibility is greater than $1 \mathrm{~km}$. 
We know that in the early stages of droplet growth the Mie attenuation factor $K$ depends strongly on the wavelength. When the drop has reached a radius $\mathrm{a} \approx 10 \lambda$ the value of $K$ approaches 2 , and the scattering is now independent of wavelength, i.e., it is non-selective. Since most of the fog droplets have radii ranging from 5 to $15 \mu \mathrm{m}$ they are comparable in size to the wavelength of infrared radiation. Consequently the value of the scattering cross section is near its maximum. It follows that the transmission of fogs in either the visible or $I R$ spectral region is poor for any reasonable path length. This of course also applies to clouds. Since haze particles are usually less than $0.5 \mu \mathrm{m}$, we note that for laser beams in the $I R$ spectral region $a / \lambda<<1$ and the scattering is not an important attenuation mechanism. This explains why photographs of distant objects are sometimes made with infrared-sensitive film that responds to wavelengths out to about $0.85 \mu \mathrm{m}$. At this wavelength the transmittance of a light haze is about twice that at $0.5 \mu \mathrm{m}$. Raindrops are of course many times larger than the wavelengths of laser beams. As a result there is no wavelength-dependent scattering.

The scattering coefficient does, however, depend strongly on the size of the drop. Middleton [5, 6] has shown that the scattering coefficient with rain is given by:

$$
\beta_{\text {rain }}=1.25 \cdot 10^{-6} \frac{\Delta x / \Delta t}{a^{3}}
$$

where $\Delta x / \Delta t$ is the rainfall rate in centimetres of depth per second and $a$ is the radius of the drops in centimetres. Rainfall rates for four different rain conditions and the corresponding transmittance (due to scattering only ) of a 1.8-km path are shown in Table 6 [2]. These data are useful for order of magnitude estimates. In order to obtain accurate estimates, the concentrations of the different types of rain drops (radius) and the associated rainfall rates should be known. In this case, the scattering coefficient can be calculated as the sum of the partial coefficients associated to the various rain drops.

Table 6. Transmittance of a $1.8-\mathrm{km}$ path through rain.

\begin{tabular}{||c|c||}
\hline Rainfall (cm/h) & Transmittance (1.8 km path) \\
\hline \hline 0.25 & 0.88 \\
\hline 1.25 & 0.74 \\
\hline 2.5 & 0.65 \\
\hline 10.0 & 0.38 \\
\hline
\end{tabular}

A simpler approach, used in LOWTRAN, gives good approximations of the results obtained with Eq. (35) for most concentrations of different rain particles. Particularly, in LOWTRAN, the scattering coefficient with rain has been empirically related only to the rainfall rate $\Delta x / \Delta t$ (expressed in $\mathrm{mm} /$ hour), as follows [7]:

$$
\beta_{\text {rain }} \approx 0.365 \cdot\left(\frac{\Delta x}{\Delta t}\right)^{0.63}
$$

Table 7 provides representative rainfall rates which can be used in Eqs. (35) and (36), when no direct measurements are available, to obtain order of magnitude estimations of $\beta_{\text {rain }}$ [8]. 
Table 7. Representative rainfall rates.

\begin{tabular}{|c|c||}
\hline Rain Intensity & Rainfall (mm/hour) \\
\hline \hline Mist & 0.025 \\
\hline Drizzle & 0.25 \\
\hline Light & 1.0 \\
\hline Moderate & 4.0 \\
\hline Heavy & 16 \\
\hline Thundershower & 40 \\
\hline Cloud-burst & 100 \\
\hline
\end{tabular}

In the presence of rain, in addition to the scattering losses calculated with Eq. (35) or (36), there are, of course, losses by absorption along the path, and these must be included in the calculation of the total atmospheric transmittance with rain.

\subsection{Combined ESLM Model}

Combining the equations presented in the paragraphs 2.3, 2.4 and 2.5, the set of equations presented in Table 8 are obtained, for calculating the one-way atmospheric transmittance $\left(\tau_{\mathrm{atm}}\right)$ in the various conditions. The cases $R_{l}$ and $R_{2}$ in Table 8 are independent of meteorological range $(V)$. Straightforward numerical analysis shows that the $\tau_{\text {atm }}$ estimates obtained with rain using Eqs. (35) and (36), are always less than the corresponding transmittance estimates obtained with Eqs. (32) and (33) with dry-air conditions and $V<6 \mathrm{~km}$, for rainfall rates $\Delta x / \Delta t \geq 1$ (i.e., from light rain to cloudburst). For double path transmission and in the general case of transmitter and receiver not collocated, the equations in Table 8 have to be modified, taking into account that the total laser path ( $\mathrm{z}$ ) is given by the sum of the range transmittertarget and target-receiver. Therefore, we have:

$$
z=R_{t}+R_{r}
$$

Denoting with the subscripts $t$ and $r$ the terms relative to the transmitting and receiving paths respectively, we have that the total atmospheric transmittance $\left(\tau_{t o t}\right)$ is given by:

$$
\tau_{t o t}=\tau_{t} \cdot \tau_{r}
$$

Therefore, in order to account for all possible cases, we have to consider the $2^{3}$ possible combinations referring to dry-air $\left(V \geq 6 \mathrm{~km} \leftrightarrow V<6 \mathrm{~km}, w_{t} \geq w_{i} \leftrightarrow w_{t}<w_{i}\right.$ and $\left.w_{r} \geq w_{i} \leftrightarrow w_{r}<w_{i}\right)$, and the $2^{2}$ combinations relative to rainy conditions $\left(w_{t} \geq w_{i} \leftrightarrow w_{t}<w_{i}\right.$ and $\left.w_{r} \geq w_{i} \leftrightarrow w_{r}<w_{i}\right)$. These combinations are given in the Tables 9 and 10 . 
Table 8. One-way transmittance equations.

\begin{tabular}{|c|c|c|c|}
\hline Case & Cond. & Eqs. & $\mathbf{n}^{\circ}$ \\
\hline $\mathbf{A}$ & $\begin{array}{c}\mathrm{V} \geq 6 \mathrm{~km} \\
\mathrm{w}>\mathrm{wi}\end{array}$ & $\tau_{\text {atm }}=k_{i} \cdot\left(\frac{w_{i}}{w}\right)^{\beta_{i}} \cdot e^{-z \cdot \frac{3.91}{V} \cdot\left(\frac{\lambda_{i}}{0.55}\right)^{-(0.0057 V+1.025)}}$ & $(3.44)$ \\
\hline B & $\begin{array}{c}\mathrm{V} \geq 6 \mathrm{~km} \\
\mathrm{w}<\mathrm{wi}\end{array}$ & $\tau_{\text {atm }}=e^{-z \cdot\left[A_{i} \sqrt{w}+\frac{3.91}{V}\left(\frac{\lambda_{i}}{0.55}\right)^{-(0.0057 \cdot V+1.025)}\right]}$ & $(3.45)$ \\
\hline C & $\begin{array}{c}\mathrm{V}<6 \mathrm{~km} \\
\mathrm{w}<\mathrm{wi}\end{array}$ & $\tau_{a t m}=e^{-z \cdot\left[A_{i} \sqrt{w}+\frac{3.91}{V}\left(\frac{\lambda_{i}}{0.55}\right)^{-0.585 \sqrt[3]{V}}\right]}$ & $(3.46)$ \\
\hline D & $\begin{array}{c}\mathrm{V}<6 \mathrm{~km} \\
\mathrm{w}>\mathrm{wi}\end{array}$ & $\tau_{\text {atm }}=k_{i} \cdot\left(\frac{w_{i}}{w}\right)^{\beta_{i}} \cdot e^{-z \cdot \frac{3.91}{V} \cdot\left(\frac{\lambda_{i}}{0.55}\right)^{-0.585 \sqrt[3]{V}}}$ & $(3.47)$ \\
\hline $\mathbf{R}_{1}$ & $\begin{array}{l}\text { Rain } \\
\mathrm{w}<\mathrm{w}_{\mathrm{i}}\end{array}$ & $\tau_{\text {atm }}=e^{-A_{i} \sqrt{w}} \cdot e^{-z \cdot\left[0.365 \cdot\left(\frac{\Delta x}{\Delta t}\right)^{0.63}\right]}$ & $(3.48)$ \\
\hline $\mathbf{R}_{2}$ & $\begin{array}{l}\text { Rain } \\
\text { w>wi }\end{array}$ & $\tau_{a t m}=k_{i}\left(\frac{w_{i}}{w}\right)^{\beta_{i}} \cdot e^{-z \cdot\left[0.365 \cdot\left(\frac{\Delta x}{\Delta t}\right)^{0.63}\right]}$ & $(3.49)$ \\
\hline
\end{tabular}

The equations presented in the Tables 8, 9 and 10 represent the combined Elder-Strong-Langer-Middleton (ESLM) model, relative to laser beam horizontal-path propagation at sea-level both in dry-air and rain conditions. The validation process of the ESLM model for NIR laser systems was undertaken during this research using experimental data collected in ground trials $(\lambda=1064 \mathrm{~nm}$ and $\lambda=1550 \mathrm{~nm})$. Furthermore, some corrections to be applied with increasing altitudes and with various laser slant-path grazing angles were determined using experimental data collected in flight trials $(\lambda=1064 \mathrm{~nm})$. The results of these activities are described in later sections of this paper. 
Table 9. ESLM-dry equations for transmitter and receiver not collocated.

\begin{tabular}{|c|c|c|c|c|}
\hline Case & Cond. & & Eqs. & $n^{\circ}$ \\
\hline $\mathbf{E}$ & $\begin{array}{l}\mathbf{V} \geq \mathbf{6} \mathbf{k m} \\
\mathbf{w}_{\mathrm{t}} \geq \mathbf{w}_{\mathrm{i}} \\
\mathbf{w}_{\mathrm{r}} \geq \mathbf{w}_{\mathrm{i}}\end{array}$ & $\begin{array}{l}k_{i}\left(\frac{w_{i}}{w_{t}}\right)^{\beta_{i}} e^{-\frac{3.91}{V}\left(\frac{\lambda_{i}}{0.55}\right)^{-(0.0057 \cdot V+1.025)} R_{t}} . \\
\cdot k_{i}\left(\frac{w_{i}}{w_{r}}\right)^{\beta_{i}} e^{-\frac{3.91}{V}\left(\frac{\lambda_{i}}{0.55}\right)^{-(0.0057 V+1.025)} R_{r}}\end{array}$ & $k_{i}^{2}\left(\frac{w_{i}^{2}}{w_{t} w_{r}}\right)^{\beta_{i}} e^{-\frac{3.91}{V}\left(\frac{\lambda_{i}}{0.55}\right)^{-(0.0057 \cdot V+1.025)}\left(R_{t}+R_{r}\right)}$ & (39) \\
\hline $\mathbf{F}$ & $\begin{aligned} \mathbf{V} \geq 6 \mathbf{k m} \\
\mathbf{w}_{\mathrm{t}} \geq \mathbf{w}_{\mathrm{i}} \\
\mathbf{w}_{\mathrm{r}}<\mathbf{w}_{\mathrm{i}}\end{aligned}$ & $\begin{array}{l}k_{i}\left(\frac{w_{i}}{w_{t}}\right)^{\beta_{i}} e^{-\frac{3.91}{V}\left(\frac{\lambda_{i}}{0.55}\right)^{-(0.0057 \cdot V+1.025)} R_{t}} \\
\cdot e^{-A_{i} \sqrt{w_{r}}-\frac{3.91}{V}\left(\frac{\lambda_{i}}{0.55}\right)^{-(0.0057 \cdot V+1.025)} R_{r}}\end{array}$ & $k_{i}\left(\frac{w_{i}}{w_{t}}\right)^{\beta_{i}} e^{-A_{i} \sqrt{w_{r}}-\frac{3.91}{V}\left(\frac{\lambda_{i}}{0.55}\right)^{-(0.0057 \cdot V+1.025)}\left(R_{t}+R_{r}\right)}$ & $(40)$ \\
\hline G & $\begin{aligned} \mathbf{V} & <6 \mathbf{k m} \\
\mathbf{w}_{\mathrm{t}} & \geq \mathbf{w}_{\mathrm{i}} \\
\mathbf{w}_{\mathrm{r}} & <\mathbf{w}_{\mathrm{i}}\end{aligned}$ & $\begin{array}{c}k_{i}\left(\frac{w_{i}}{w_{t}}\right)^{\beta_{i}} e^{-\frac{3.91}{V}\left(\frac{\lambda_{i}}{0.55}\right)^{-0.585 \sqrt[3]{V}} R_{t}} . \\
\cdot e^{-A_{i} \sqrt{w_{r}}-\frac{3.91}{V}\left(\frac{\lambda_{i}}{0.55}\right)^{-0.585 \sqrt[3]{V}} R_{r}}\end{array}$ & $k_{i}\left(\frac{w_{i}}{w_{t}}\right)^{\beta_{i}} e^{-A_{i} \sqrt{w_{r}}-\frac{3.91}{V}\left(\frac{\lambda_{i}}{0.55}\right)^{-0.585 \sqrt[3]{V}}\left(R_{t}+R_{r}\right)}$ & (41) \\
\hline H & $\begin{array}{l}\mathrm{V}<6 \mathbf{k m} \\
\mathbf{w}_{\mathrm{t}} \geq \mathbf{w}_{\mathrm{i}} \\
\mathrm{w}_{\mathrm{r}} \geq \mathrm{w}_{\mathrm{i}}\end{array}$ & $\begin{array}{l}k_{i}\left(\frac{w_{i}}{w_{t}}\right)^{\beta_{i}} e^{-\frac{3.91}{V}\left(\frac{\lambda_{i}}{0.55}\right)^{-0.585 \sqrt[3]{V}} R_{t}} . \\
k_{i}\left(\frac{w_{i}}{w_{r}}\right)^{\beta_{i}} e^{-\frac{3.91}{V}\left(\frac{\lambda_{i}}{0.55}\right)^{-0.585 \sqrt[3]{V}} R_{r}}\end{array}$ & $k_{i}^{2}\left(\frac{w_{i}^{2}}{w_{t} w_{r}}\right)^{\beta_{i}} e^{-\frac{3.91}{V}\left(\frac{\lambda_{i}}{0.55}\right)^{-0.585 \sqrt[3]{V}}\left(R_{t}+R_{r}\right)}$ & (42) \\
\hline I & $\begin{array}{l}\mathbf{V} \geq \mathbf{6} \mathbf{k m} \\
\mathbf{w}_{\mathbf{t}}<\mathbf{w}_{\mathbf{i}} \\
\mathbf{w}_{\mathbf{r}} \geq \mathbf{w}_{\mathbf{i}}\end{array}$ & $\begin{array}{c}e^{-A_{i} \sqrt{w_{t}}-\frac{3.91}{V}\left(\frac{\lambda_{i}}{0.55}\right)^{-(0.0057 \cdot V+1.025)} R_{t}} . \\
k_{i}\left(\frac{w_{i}}{w_{r}}\right)^{\beta_{i}} e^{-\frac{3.91}{V}\left(\frac{\lambda_{i}}{0.55}\right)^{-(0.0057 \cdot V+1.025)} R_{r}}\end{array}$ & $k_{i}\left(\frac{w_{i}}{w_{r}}\right)^{\beta_{i}} e^{-A_{i} \sqrt{w_{t}}-\frac{3.91}{V}\left(\frac{\lambda_{i}}{0.55}\right)^{-(0.0057 \cdot V+1.025)}\left(R_{t}+R_{r}\right)}$ & (43) \\
\hline $\mathbf{J}$ & $\begin{aligned} \mathbf{V} \geq 6 \mathbf{k m} \\
\mathbf{w}_{\mathrm{t}}<\mathbf{w}_{\mathrm{i}} \\
\mathbf{w}_{\mathbf{r}}<\mathbf{w}_{\mathrm{i}}\end{aligned}$ & $\begin{array}{c}e^{-A_{i} \sqrt{w_{t}}-\frac{3.91}{V}\left(\frac{\lambda_{i}}{0.55}\right)^{-(0.0057 \cdot V+1.025)} R_{t}} . \\
\cdot e^{-A_{i} \sqrt{w_{r}}-\frac{3.91}{V}\left(\frac{\lambda_{i}}{0.55}\right)^{-(0.0057 \cdot V+1.025)} R_{r}}\end{array}$ & $e^{-A_{i} \sqrt{w_{t}}-A_{i} \sqrt{w_{r}}-\frac{3.91}{V}\left(\frac{\lambda_{i}}{0.55}\right)^{-(0.0057 \cdot V+1.025)}\left(R_{t}+R_{r}\right)}$ & (44) \\
\hline $\mathbf{K}$ & $\begin{aligned} \mathrm{V} & <6 \mathbf{k m} \\
\mathbf{w}_{\mathrm{t}} & <\mathrm{w}_{\mathrm{i}} \\
\mathbf{w}_{\mathrm{r}} & <\mathbf{w}_{\mathrm{i}}\end{aligned}$ & $\begin{array}{c}e^{-A_{i} \sqrt{w_{t}}-\frac{3.91}{V}\left(\frac{\lambda_{i}}{0.55}\right)^{-0.585 \sqrt[3]{V}} R_{t}} . \\
\cdot e^{-A_{i} \sqrt{w_{r}}-\frac{3.91}{V}\left(\frac{\lambda_{i}}{0.55}\right)^{-0.585 \sqrt[3]{V}} R_{r}}\end{array}$ & $e^{-A_{i} \sqrt{w_{t}}-A_{i} \sqrt{w_{r}}-\frac{3.91}{V}\left(\frac{\lambda_{i}}{0.55}\right)^{-0.585 \sqrt[3]{V}}\left(R_{t}+R_{r}\right)}$ & (45) \\
\hline $\mathbf{L}$ & $\begin{array}{l}\mathrm{V}<6 \mathbf{k m} \\
\mathbf{w}_{\mathrm{t}}<\mathrm{w}_{\mathrm{i}} \\
\mathrm{w}_{\mathrm{r}} \geq \mathrm{w}_{\mathrm{i}}\end{array}$ & $\begin{array}{c}e^{-A_{i} \sqrt{w_{t}}-\frac{3.91}{V}\left(\frac{\lambda_{i}}{0.55}\right)^{-0.585 \sqrt[3]{V}} R_{t}} \\
\cdot k_{i}\left(\frac{w_{i}}{w_{r}}\right)^{\beta_{i}} e^{-\frac{3.91}{V}\left(\frac{\lambda_{i}}{0.55}\right)^{-0.585 \sqrt[3]{V}}} R_{r}\end{array}$ & $k_{i}\left(\frac{w_{i}}{w_{r}}\right)^{\beta_{i}} e^{-A_{i} \sqrt{w_{t}}-\frac{3.91}{V}\left(\frac{\lambda_{i}}{0.55}\right)^{-0.585 \sqrt[3]{V}}\left(R_{t}+R_{r}\right)}$ & (46) \\
\hline
\end{tabular}


Table 10. ESLM-rain equations for transmitter and receiver not collocated.

\begin{tabular}{|c|c|c|c|c|}
\hline Case & Cond. & & Eqs. & $\mathbf{n}^{\circ}$ \\
\hline $\mathrm{R}_{3}$ & $\begin{array}{c}\text { Rain } \\
\mathbf{w}_{\mathrm{t}} \geq \mathbf{w}_{\mathbf{i}} \\
\mathbf{w}_{\mathrm{r}} \geq \mathbf{w}_{\mathbf{i}}\end{array}$ & $\begin{array}{l}k_{i}\left(\frac{w_{i}}{w_{t}}\right)^{\beta_{i}} e^{-0.365\left(\frac{\Delta x}{\Delta t}\right)^{0.63} R_{t}} \\
k_{i}\left(\frac{w_{i}}{w_{r}}\right)^{\beta_{i}} e^{-0,365\left(\frac{\Delta x}{\Delta t}\right)^{0.63} R_{r}}\end{array}$ & $k_{i}^{2}\left(\frac{w_{i}^{2}}{w_{t} w_{r}}\right)^{\beta_{i}} e^{-0.365\left(\frac{\Delta x}{\Delta t}\right)^{0.63}\left(R_{t}+R_{r}\right)}$ & (47) \\
\hline $\mathrm{R}_{4}$ & $\begin{array}{c}\text { Rain } \\
\mathbf{w}_{\mathbf{t}} \geq \mathbf{w}_{\mathbf{i}} \\
\mathbf{w}_{\mathbf{r}}<\mathbf{w}_{\mathbf{i}}\end{array}$ & $\begin{array}{c}k_{i}\left(\frac{w_{i}}{w_{t}}\right)^{\beta_{i}} e^{-0.365\left(\frac{\Delta x}{\Delta t}\right)^{0.63} R_{t}} . \\
\cdot e^{-A_{i} \sqrt{w_{r}}-0.365\left(\frac{\Delta x}{\Delta t}\right)^{0.63} R_{r}}\end{array}$ & $k_{i}\left(\frac{w_{i}}{w_{t}}\right)^{\beta_{i}} e^{-A_{i} \sqrt{w_{r}}-0.365\left(\frac{\Delta x}{\Delta t}\right)^{0.63}\left(R_{t}+R_{r}\right)}$ & (48) \\
\hline $\mathrm{R}_{5}$ & $\begin{array}{c}\text { Rain } \\
\mathbf{w}_{\mathbf{t}}<\mathbf{w}_{\mathbf{i}} \\
\mathbf{w}_{\mathbf{r}} \geq \mathbf{w}_{\mathbf{i}}\end{array}$ & $\begin{array}{c}e^{-A_{i} \sqrt{w_{t}}-0.365\left(\frac{\Delta x}{\Delta t}\right)^{0.63} R_{t}} \\
k_{i}\left(\frac{w_{i}}{w_{r}}\right)^{\beta_{i}} e^{-0.365\left(\frac{\Delta x}{\Delta t}\right)^{0.63} R_{r}}\end{array}$ & $k_{i}\left(\frac{w_{i}}{w_{r}}\right)^{\beta_{i}} e^{-A_{i} \sqrt{w_{t}}-0.365\left(\frac{\Delta x}{\Delta t}\right)^{0.63}\left(R_{t}+R_{r}\right)}$ & (49) \\
\hline $\mathrm{R}_{6}$ & $\begin{array}{c}\text { Rain } \\
\mathbf{w}_{\mathbf{t}}<\mathbf{w}_{\mathbf{i}} \\
\mathbf{w}_{\mathbf{r}}<\mathbf{w}_{\mathbf{i}}\end{array}$ & $\begin{array}{l}e^{-A_{i} \sqrt{w_{t}}-0.365\left(\frac{\Delta x}{\Delta t}\right)^{0.63} R_{t}} \\
\cdot e^{-A_{i} \sqrt{w_{r}}-0.365\left(\frac{\Delta x}{\Delta t}\right)^{0.63} R_{r}}\end{array}$ & $e^{-A_{i}\left(\sqrt{w_{t}}-\sqrt{w_{r}}\right)-0.365\left(\frac{\Delta x}{\Delta t}\right)^{0.63}\left(R_{t}+R_{r}\right)}$ & (50) \\
\hline
\end{tabular}

\subsection{Other Propagation Effects}

As briefly illustrated in the previous paragraphs, a laser beam is attenuated as it propagates through the atmosphere, mainly due to absorption and scattering phenomena. In addition, the beam is often broadened, defocused, and may be deflected from its initial propagation direction. These atmospheric effects have important consequences for the use of lasers in remote sensing. Particularly, remote sensing laser systems are required to identify and quantify the combined effects of these propagation phenomena, in order to compute molecular species and aerosol particle concentrations. The attenuation and amount of beam alteration of a laser beam propagating in a planetary atmosphere depend on the wavelength of operation, the output power and indeed the characteristics of the atmosphere. When the output power is low, the effects tend to be linear in behaviour. That is, doubling the initial beam intensity results in a doubled intensity at every point along the propagation path. Absorption, scattering, and atmospheric turbulence are examples of linear effects. On the other hand, when the power is sufficiently high, new effects are observed that are characterized by nonlinear relationships. Some important non-linear effects are thermal blooming, kinetic cooling, beam trapping, twophoton absorption, bleaching, and atmospheric breakdown, which, incidentally, fix an upper limit on the intensity that can be transmitted. In all cases the effects can be significant and severely affect laser beam propagation in the atmosphere.

\subsection{Global Model for Atmospheric Transmission}

For our applications, it is necessary to determine the peak irradiance in the focal plane. In this section we describe a method for calculating the mean peak focal irradiance due to diffraction, random jitter, atmospheric turbulence, and thermal blooming. We assume for convenience a Gaussian beam at the source and an average focused irradiance, which 
because of beam jitter and turbulence-induced spreading also has a Gaussian distribution. The peak irradiance for such a beam is [9]:

$$
I_{p}=\frac{P e^{-\gamma z}}{\pi\left(a_{d}^{2}+a_{j}^{2}+a_{t}^{2}\right)}
$$

where $P$ is the output power, $\gamma$ is the attenuation coefficient, $a$ is the $1 / e$ beam radius, and the subscripts $d$, $j$, and $t$ refer to diffraction, jitter, and turbulence. The contributions to the focal spot area due to diffraction, jitter, and turbulence are, respectively, given by:

$$
\begin{aligned}
& a_{d}^{2}=\left(Q z \lambda / 2 \pi a_{0}\right)^{2} \\
& a_{j}^{2}=2<\theta_{x}^{2}>z^{2} \\
& a_{t}^{2}=\frac{4 C_{N}^{12 / 5} z^{16 / 5}}{\lambda^{2 / 5}}
\end{aligned}
$$

where $Q$ is the beam quality factor (i.e., the observed beam radius divided by the diffraction- limited radius), and $\left.<\theta_{x}^{2}\right\rangle$ is the variance of the single axis jitter angle that is assumed to be equal to $<\theta_{y}^{2}>$. In order to account for the thermal blooming effect, Eq. (9) is modified as follows:

$$
I_{p}=\frac{P e^{-r z}}{\pi\left(a_{d}^{2}+a_{j}^{2}+a_{t}^{2}\right)} \times R
$$

where $R$ is the ratio of the bloomed $I_{B}$ to unbloomed $I_{U B}$ peak irradiance. An empirical relationship for $R$ found for propagation in the Earth's atmosphere is the following:

$$
R=\frac{I_{B}}{I_{U B}}=\frac{1}{1+0.0625 N^{2}}
$$

where $N$, the thermal distortion parameter, is a dimensionless quantity that indicates the degree or strength of thermal distortion. Here $N$ is given by:

$$
N=N_{0}\left[\frac{2}{z^{2}} \int_{0}^{z} \frac{a_{0}}{a\left(z^{\prime}\right)} d z^{\prime} \int_{0}^{z^{\prime}} \frac{a_{0}^{2} v_{0} \exp \left(-\gamma z^{\prime \prime}\right)}{a^{2}\left(z^{\prime \prime}\right) v\left(z^{\prime \prime}\right)} d z^{\prime \prime}\right]
$$

where

$$
N_{0}=\frac{-n_{T} \alpha_{m} P z^{2}}{\pi d_{0} v_{0} c_{p} a_{0}^{3}}
$$

is the distortion parameter for a collimated Gaussian beam of 1/e radius $a_{0}$ and uniform wind velocity $v_{0}$ in the weak attenuation limit $(\gamma z<1)$. The quantities $n_{T}, d_{0}$, and $c_{p}$ are, respectively, the coefficients of index change with respect to temperature, density, and specific heat at constant pressure, and $P$ and $z$ are the laser output power and range, respectively. Eq. (13) is the propagation equation for Gaussian beams. It can be used to compare the propagation performance of different laser wavelengths. Considering both propagation performances and output power characteristics of state-of-the-art systems, good candidate lasers covering the entire infrared spectrum are listed below:

- $\mathrm{CO}_{2} \rightarrow \lambda=10.591 \mu \mathrm{m}$

- $\mathrm{CO} \rightarrow \lambda=4.9890 \mu \mathrm{m}$

- DF $\rightarrow \lambda=3.8007 \mu \mathrm{m}$

- $\mathrm{HF} \rightarrow \lambda=2.9573 \mu \mathrm{m}$

- Er:Fiber $\rightarrow \lambda=1.5500 \mu \mathrm{m}$

- Nd:YAG $\rightarrow \lambda=1.0640 \mu \mathrm{m}$

- $\mathrm{Ar} \quad \rightarrow \lambda=0.5145 \mu \mathrm{m}$

- $\mathrm{N}_{2} \quad \rightarrow \lambda=0.3371 \mu \mathrm{m}$ 
In general, for the mid to far-IR lasers (e.g., $\mathrm{CO}_{2}, \mathrm{CO}$ and DF) the peak irradiance increases with decreasing wavelength in clear and moderate turbulence conditions. For the near to mid-IR lasers (eg., HF, Ar, and Nd:YAG lasers), the peak irradiance is reduced significantly by aerosol scattering and turbulence. It is interesting to note that for the $\mathrm{CO}_{2}$ wavelength, which is dominated by thermal blooming due to stronger molecular absorption, the peak irradiance is relatively insensitive to both turbulence and aerosol effects. At the shorter wavelengths the effects of turbulence and aerosol attenuation produce wide variations in the peak irradiance. The importance of both aerosol scattering and turbulence effects clearly increases at the shorter wavelengths (eg., Ar, $\mathrm{N}_{2}$, Er:Fiber and Nd:YAG lasers). In most cases, the near to mid-IR regions offer the best overall transmission characteristics; in particular, the $3.8-\mu \mathrm{m}$ DF wavelength is optimum for varying aerosol and turbulence conditions. In summary, the propagation of high-power laser beams through the atmosphere is affected by a host of optical phenomena. For CW beams the most significant phenomena are absorption and scattering by molecules and aerosols, as well as atmospheric turbulence and thermal blooming. In general, thermal blooming tends to dominate the longer wavelengths $(5-10 \mu \mathrm{m})$, while aerosol and turbulence effects are more important at the shorter wavelengths and result in larger variations in peak irradiance in the focal plane as atmospheric conditions change. Some of these effects can be overcome by using laser pulses rather than CW beams and/or adaptive optical techniques.

\section{SOUNDING TECHNIQUES}

The techniques that we propose are suitable for remote sensing missions performed by using aircraft, satellites, Unmanned Aerial Vehicles (UAV), parachute/gliding vehicles, Roving Surface Vehicles (RSV), or Permanent Surface Installations (PSI). They are based on direct measurement of the laser energy incident on target surfaces of known geometric and reflective characteristics, such as Spectral Reflectance $(\rho)$ and Bidirectional Reflectance Distribution Function (BRDF). Possible platform applications are depicted in Fig. 3.

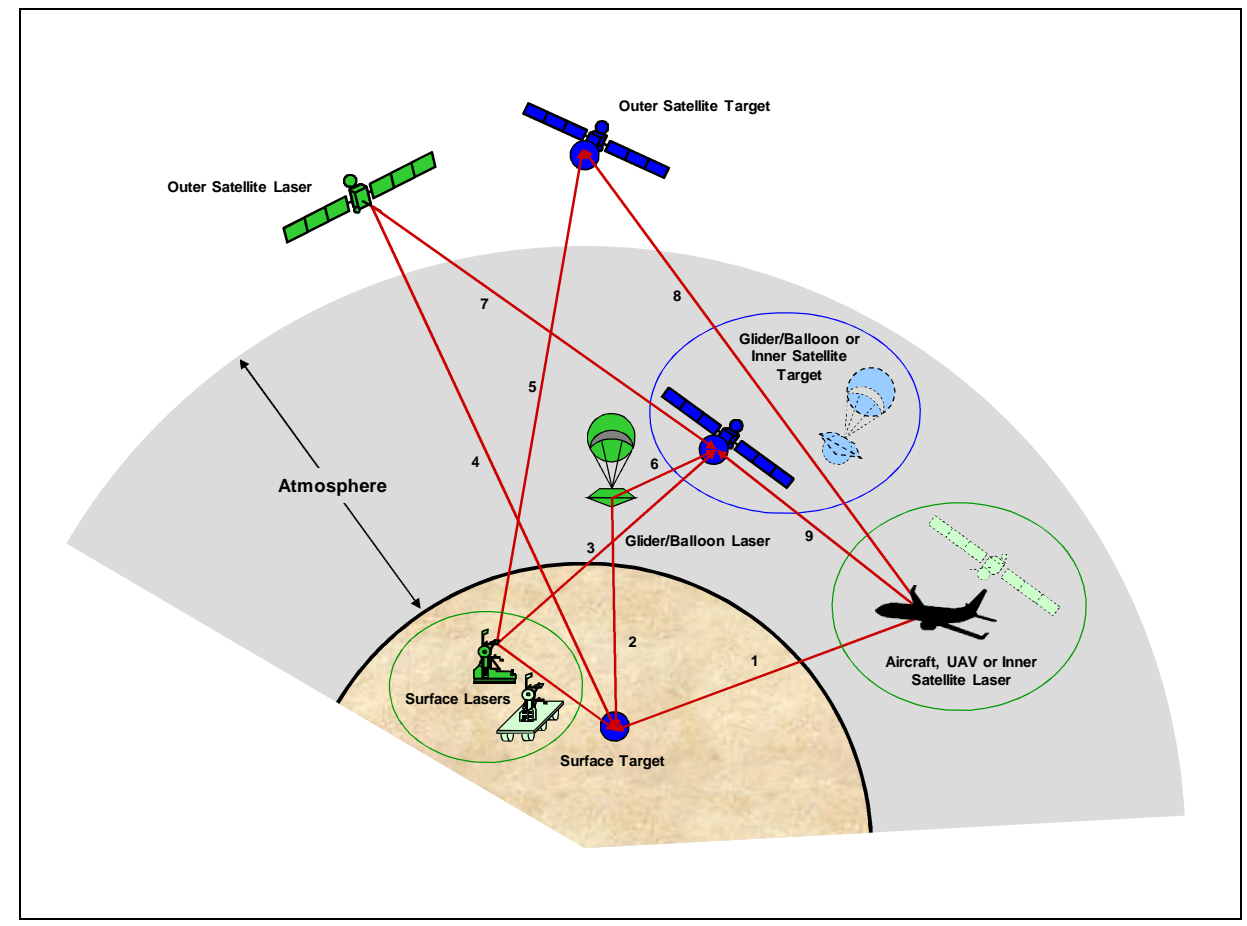

Figure 3. Possible platform applications.

For vertical/oblique paths sounding, the laser source can be located on Satellites (GEO, MEO and LEO), Gliders or UFVs flying in the planet atmosphere at different altitudes (but also manned aircrafts on Earth or their future equivalents 
on other planets), while for surface layer measurements the laser source could be mounted on RSV or even on PSI turrets at different fixed locations on the planet surface.

\subsection{Particle Retrieval}

The majority of established retrieval approaches make use of LIDAR systems to measure atmospheric transmission parameters at various wavelengths and then use various algorithms to retrieve atmospheric constituents from the collected data. These systems often employ sophisticated processing including frequency, amplitude and polarization analysis techniques to retrieve atmospheric components information. We start our discussion of a possible alternative to existing LIDAR systems proposing that the atmospheric transmittances of particular NIR laser wavelengths are measured directly using passive NIR imaging systems and, based on these measurement, the atmospheric gas/particle concentrations are retrieved using appropriate estimation algorithms. Particularly, laser beams of known output power, polarization state, and geometry (e.g., Gaussian profile) are aimed at a target of known spectral reflectance and BRDF, located at known distances from the laser sources. The data accumulated in a certain time period are then processed in order to obtain the desired atmospheric components concentrations. The difficulty in developing inversion algorithms lies in the fact that the input optical data are connected to the investigated microphysical parameters through non-linear integral equations of the first kind (Fredholm equations), which cannot be solved analytically. A general form of the Fredholm equation for atmospheric data retrieval is:

$$
\alpha(\lambda), \beta(\lambda)=\int K_{\alpha, \beta}(\mathrm{r}, \mathrm{n}, \mathrm{k}, \lambda) \mathrm{D}(\mathrm{r}) \mathrm{dr}
$$

where $\alpha(\lambda)$ and $\beta(\lambda)$ represent the optical data, $K_{\alpha \beta}$ is the atmospheric kernel function (containing information on particle size, particle refractive index, etc.) and $D(r)$ is the particle size distribution. The numerical solution of these equations leads to the so called ill-posed inverse problem. Such problems are characterized by a strong sensitivity of the solution space toward uncertainties of the input data, the non-uniqueness of the solution space, and the incompleteness of the solution space. In fact, the solution space may still be correct in a mathematical sense, but might not necessarily reflect the physical conditions. As the problem cannot be entirely defined by the measurements, a priori knowledge of the state vector is required in order to determine the most probable solution, with a probabilistic Bayesian approach. Let $\mathbf{y}$ be the measurement vector containing the measured radiances, and $\mathbf{x}$ be the concentration of a given constituent, then the general remote sensing equation can be written as follows [12]:

$$
y=\mathrm{f}(x, b)+\varepsilon
$$

where $f$ represents the forward transfer function, $\mathbf{b}$ the other parameters having an impact on the measurement, and $\mathbf{\varepsilon}$ the measurement noise. In the case of a NIR sounding instrument measuring laser radiance, the vector $\mathbf{b}$ includes the target surface reflective and radiative features (BRDF, reflectivity, emissivity and temperature), variables describing the state of the atmosphere (vertical profiles of atmospheric turbulence, temperature, water vapor and other atmospheric constituents, clouds, aerosols, etc.), and some characteristics of the measurement instruments (spectral response functions and resolution). The inverse problem consists in retrieving $\hat{\mathbf{x}}$, an estimate of the true state $\mathbf{x}$, from the measurement $\mathbf{y}$, and can be written:

$$
\hat{x}=\mathrm{R}(y, \hat{b})=\mathrm{R}(\mathrm{f}(x, b)+\varepsilon, \hat{b})
$$

where $\hat{\mathbf{b}}$ is an estimate of the non-retrieved parameters $\mathbf{b}$, and $R$ is the inverse transfer function. This a priori information consists of an a priori state vector $\mathbf{x}_{\mathbf{a}}$ and its covariance matrix $\mathbf{S}_{\mathbf{a}}$, which may be provided by model simulations. Therefore, the inverse problem can be rewritten as follows:

$$
\hat{x}=\mathrm{R}\left(y, \hat{b}, x_{a}\right)
$$

Various inversion techniques are available. One of the most popular approaches is inversion with regularization, offering the advantage of reducing oscillations in the solutions that are frequently experienced in data retrieved from electro-optical measurements [9, 10]. This approach consists in introducing constraints, such as derivative analysis (smoothness) of the particle size distribution functions, positive sign of the functions and maximum variations over time. Using appropriate kernel/base functions, this algorithm can deliver parameters such as effective (average) particle radius, particle size distribution, total surface-area concentration, total number/volume concentrations, refractive index real and 
imaginary parts, single scattering albedo, etc. The base functions are Gaussian fits of existing particle concentrations data and are used to reconstruct the investigated particle size distributions. The kernel functions describe the interaction of laser radiation with the atmosphere and contain information about the atmospheric transmittance, including scattering and absorption processes. A schematic of this inversion algorithm is shown in Fig. 4.

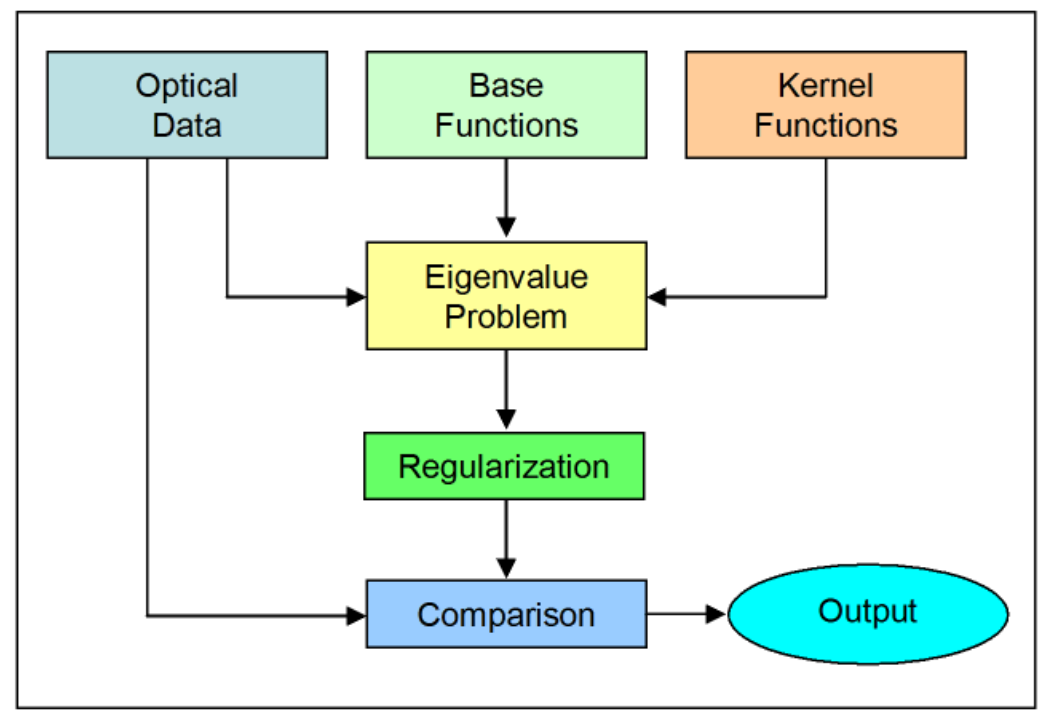

Figure 4. Inversion with regularization algorithm.

\section{2 $\mathrm{CO}_{2}$ Retrieval}

As discussed in earlier sections, one of the objectives of this research is to develop techniques for $\mathrm{CO}_{2}$ column density measurements performed from aircraft and ground installations, with a capability of scaling to permit measurements over extended regions from satellites as well. For single-path transmission, the absorptive transmittance is related to the total column $\mathrm{CO}_{2}$ density by:

$$
\tau_{a b s}=\tau_{o f f} \exp \left(-\int_{0}^{\mathrm{R}}\left[\sigma(\lambda, r)-\sigma\left(\lambda_{o f f}, r\right)\right] n_{C O 2}(r) d r\right)
$$

where $\tau_{\text {off }}$ is the transmittance for a NIR laser wavelength off the absorption line, $\sigma(\lambda, r)$ is the $\mathrm{CO}_{2}$ molecular absorption cross-section at the laser wavelength $\lambda$ and range $r, \sigma\left(\lambda_{\text {off }}, r\right)$ is the offline $\mathrm{CO}_{2}$ absorption cross-section, and $n_{\mathbf{C O} 2}(r)$ is the $\mathrm{CO}_{2}$ molecular volume density. For airborne measurements through a vertical path, the pressure and temperature both change with $r$. The varying pressure and temperature change the line shape and causes $\sigma(\lambda, r)$ to vary with range, and hence cause an altitude dependence (or weighting) in absorption. Assuming the simplest case when the path temperature and pressure conditions are approximately uniform, the line shape and cross-sections are about constant along the path. Therefore, we have:

$$
\tau_{a b s}=\tau_{o f f} \exp \left(-\left[\sigma(\lambda)-\sigma\left(\lambda_{o f f}\right)\right] \int_{0}^{\mathrm{R}} n_{C O 2}(r) d r\right)
$$

For this simple case and using a single wavelength for the online measurement $\left(\lambda_{o n}\right)$, we can compute the total column $\mathrm{CO}_{2}$ abundance $\left(N_{\mathrm{co} 2}\right)$ from the ratio of the laser energy $(E)$ measured at a distance $r$ on- and off-line from the $\mathrm{CO}_{2}$ absorption wavelength $\left(R_{\text {on-off }}\right)$. In fact:

$$
R_{\text {on-off }}=\frac{E\left(\lambda_{\text {off }}\right)}{E\left(\lambda_{\text {on }}\right)}=\exp \left(-\left[\sigma\left(\lambda_{o n}\right)-\sigma\left(\lambda_{\text {off }}\right)\right] \int_{0}^{\mathrm{R}} n_{C O 2}(r) d r\right)
$$


Therefore:

$$
N_{\mathrm{CO} 2}=\int_{0}^{\mathrm{R}} n_{\mathrm{CO} 2}(r) d r=-\frac{\ln \left(R_{\text {on-off }}\right)}{\left[\sigma\left(\lambda_{\text {on }}\right)-\sigma\left(\lambda_{\text {off }}\right)\right]}
$$

The optical depth of the line absorption is the quantity $-\ln \left(R_{\text {on-off }}\right)$. In our case, we have defined $R_{\text {on-off }}$ as the ratio of the received laser energy measured for the on- and off-line wavelengths. This is a significant advantage over traditional wavelength-stepped LIDAR systems, where $R_{\text {on-off }}$ must be multiplied by fractions which depends on the LIDAR frequency response and SNR [15]. Equation (58) assumes that the surface reflectivity $(\rho)$ and BRDF are equal at both wavelengths. This is an acceptable approximation for the techniques that we propose, especially using contiguous wavelengths and a uniform reference surface with known reflective characteristics. However, this is not true for a wavelength-stepped LIDAR system measuring from a moving aircraft, particularly if the surface area (and reflectivity) viewed by the LIDAR changes at an appreciable fraction of the LIDAR wavelength step rate [17]. Additionally, our techniques allow for suitable mathematical models, fed by sufficiently accurate meteorological data along the transmission path, to be used for the determination of atmospheric extinction at the reference wavelengths both at sealevel and as a function of altitude.

\section{TRANSMITTANCE MEASUREMENT TECHNIQUES}

We propose various methods for accurate Laser Transmittance Measurement (LTM) that use combinations of different pulsed laser sources, direct detection electro-optics systems, and passive infrared imaging systems. The proposed methods are suitable for both Earth remote sensing missions and likely future planetary exploration missions performed by using Satellites, Unmanned Flight Vehicles (UFV), Gliders/Parachutes/Balloons (GPB), Roving Surface Vehicles (RSV), or Permanent Surface Installations (PSI). For vertical/oblique paths sounding, the laser source can be located on Satellites (GEO, MEO and LEO) or UFV flying in the planet atmosphere at different altitudes (but also manned aircrafts on Earth or their future equivalents on other planets), while for surface layer measurements the laser source could be mounted on RSV or even on PSI turrets at different fixed locations on the planet surface. All proposed methods offer relative advantages and limitations in different scenarios. All are based on measurements of the laser energy (intensity and spatial distribution) incident on target surfaces of known geometric and reflective characteristics, by means of infrared detectors and/or infrared cameras calibrated for radiance.

\subsection{LTM-A Method}

The first method proposed (LTM-A) is illustrated in Fig. 5. A laser beam of output power $\left(P_{01}\right)$ is aimed at a target of known spectral reflectance $(\rho)$ and diffuse BRDF, located at a known distance $\left(d_{1}\right)$ from the laser source. The reflected laser radiation is measured at the source location as a detector output voltage $\left(V_{l}\right)$. Successively, the laser (with output $P_{02} \neq P_{01}$ in general, due to output power fluctuations) is fired towards a second target of identical characteristics located at a longer distance $\left(d_{2}\right)$ and the detector output voltage $\left(V_{2}\right)$ is measured again. Using these data, atmospheric extinction $(\gamma)$ can be computed using the algorithms described here. In general, the function describing the anodic voltage at the receiver can be expressed in the form:

$$
V_{A}=R_{L} \cdot R_{S} \cdot P
$$

where $V$ is the anodic voltage, $R_{L}$ is the anodic load $(\Omega), R_{S}$ is the detector responsivity $(A / W)$, and $P_{R}$ is the power reaching the receiver detector $(W)$. Assuming an extended target, the power at the detector can be expressed as:

$$
P=K_{S Y S} \cdot \rho \cdot \frac{1}{d_{0}{ }^{2}} \cdot e^{-2 \gamma d_{0}}
$$

where $\rho$ is the target reflectivity, $d_{0}$ is the distance of the target from the transmitter/receiver, and $\gamma$ is the extinction coefficient. $K_{S Y S}$ is a constant which accounts for all relevant transmitter/receiver systems parameters (e.g., transmitted laser power $\left(P_{0}\right)$, efficiency of the transmitting and receiving optics $\left(\eta_{T X}, \eta_{R X}\right)$, output beam diameter and divergence $\left(D_{L}\right.$, $\alpha_{T}$ ), transmitter/receiver LOS geometry, etc.). 


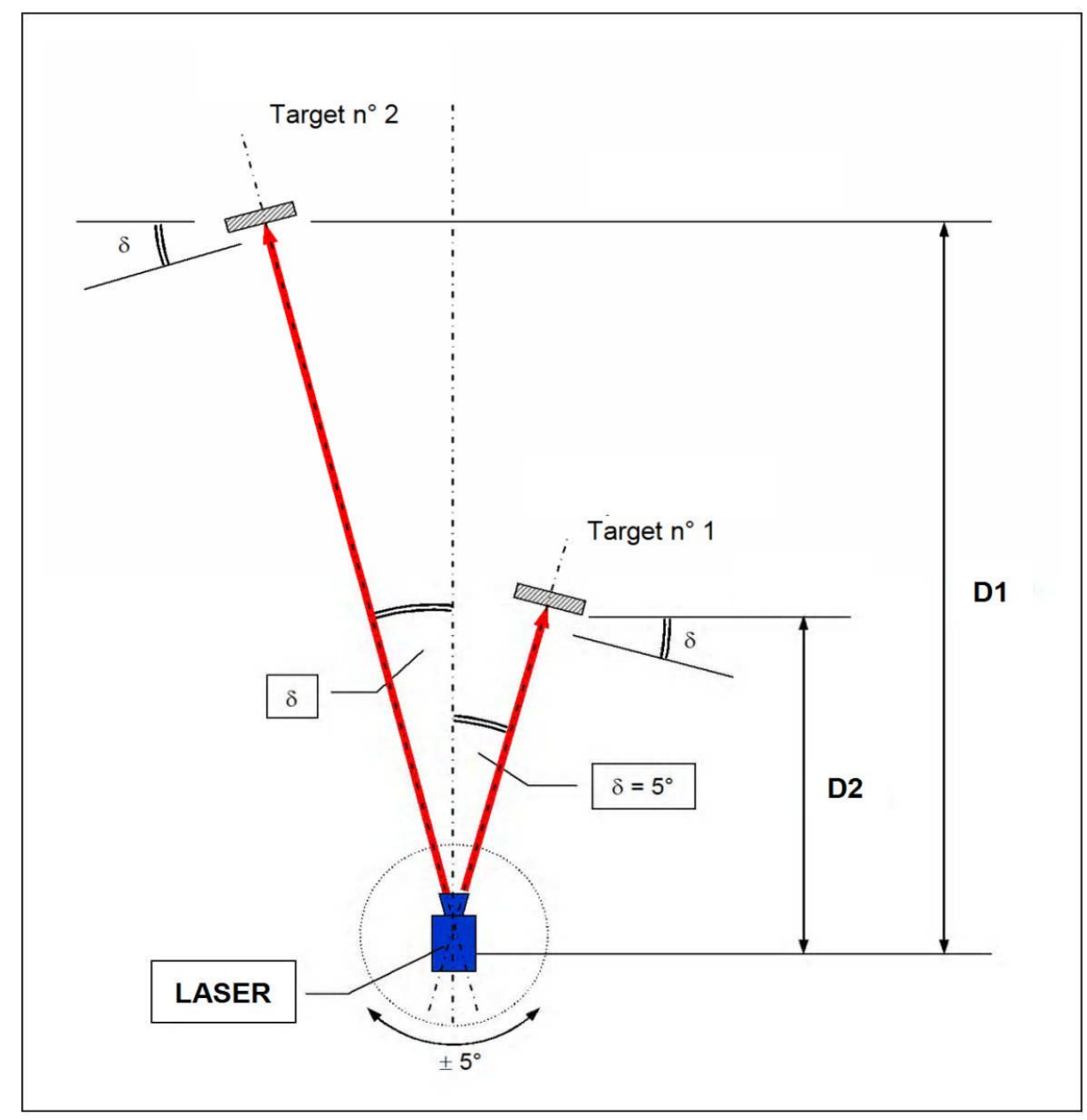

Figure 5. LAS-A Method.

Therefore, using two identical Lambertian targets placed at slant-ranges $d_{1}$ and $d_{2}$ respectively from the laser transmitter/receiver with a similar LOS geometry, and assuming that the extinction coefficient is constant in the slantranges considered, the following expressions can be written for the two anodic voltages measured at the receiver using target $\mathrm{n}^{\circ} 1\left(V_{1}\right)$ and target $\mathrm{n}^{\circ} 2\left(V_{2}\right)$ :

$$
\begin{aligned}
& V_{1}=R_{L} \cdot R_{S} \cdot\left(K_{S Y S} \cdot \rho \cdot \frac{1}{d_{1}^{2}} \cdot e^{-2 \gamma d_{1}}\right) \\
& V_{2}=R_{L} \cdot R_{S} \cdot\left(K_{S Y S} \cdot \rho \cdot \frac{1}{d_{2}^{2}} \cdot e^{-2 \gamma d_{2}}\right)
\end{aligned}
$$

It is reasonable to assume that, measuring the anodic voltages $V_{l}$ and $V_{2}$, all system parameters remain constant, except the transmitted laser power $\left(P_{0}\right)$ which may vary significantly in the time intervals where the two measurement sessions are performed. With these assumptions, we can write the following expressions:

$$
\begin{aligned}
& V_{1}=K \cdot P_{01} \cdot \frac{e^{-2 \gamma d_{1}}}{d_{1}{ }^{2}} \\
& V_{2}=K \cdot P_{02} \cdot \frac{e^{-2 \gamma d_{2}}}{d_{2}{ }^{2}}
\end{aligned}
$$


where $P_{01}$ and $P_{02}$ are the transmitted laser powers, and the factor $K$ contains all constant terms. Therefore:

$$
\frac{V_{1}}{V_{2}}=\frac{P_{01}}{P_{02}} \cdot \frac{d_{2}^{2}}{d_{1}^{2}} \cdot e^{2 \gamma\left(d_{2}-d_{1}\right)}
$$

Finally, we obtain:

$$
\gamma=\frac{1}{2 \Delta d} \cdot \ln \left[\frac{\left(\frac{V_{1}}{P_{01}}\right) \cdot d_{1}{ }^{2}}{\left(\frac{V_{2}}{P_{02}}\right) \cdot d_{2}{ }^{2}}\right]
$$

where the difference of the system to target slant-ranges $\left(d_{1}-d_{2}\right)$ has been replaced by the symbol $\Delta d$. It should be noted that all parameters contributing to the constant $K$ do not affect the measurements (i.e., knowledge of these parameters is not required if their value remains constant during the measurements performed on target $n^{\circ} 1$ and $n^{\circ} 2$ ). Obviously, the accuracy in the measurement of $\gamma$ is affected by: 1) the error in measuring the distances $d_{1}$ and $d_{2}$;2) the error in measuring the voltages $V_{1}$ and $V_{2}$; and 3) the error in measuring the powers $P_{01}$ and $P_{02}$. Therefore, considering the errors relative to the measured parameters $\left(\sigma_{d 1}, \sigma_{d 2}, \sigma_{V 1}, \sigma_{V 2}, \sigma_{P 01}, \sigma_{P 02}\right)$, we can write:

$$
\begin{aligned}
\sigma_{\gamma}{ }^{2}= & \frac{1}{(2 \Delta d)^{2}} \cdot\left(\frac{\sigma_{V_{1}}{ }^{2}}{V_{1}{ }^{2}}+\frac{\sigma_{V_{2}}{ }^{2}}{V_{2}{ }^{2}}\right)+\frac{1}{(2 \Delta d)^{2}} \cdot\left(\frac{\sigma_{P_{01}}{ }^{2}}{P_{01}{ }^{2}}+\frac{\sigma_{P_{02}}{ }^{2}}{P_{02}{ }^{2}}\right)+ \\
& +\frac{\gamma^{2}}{\Delta d^{2}} \cdot\left(d_{2}+\frac{1}{\gamma}\right)^{2} \cdot \frac{\sigma_{d_{2}}{ }^{2}}{d_{2}{ }^{2}}+\frac{\gamma^{2}}{\Delta d^{2}} \cdot\left(d_{1}+\frac{1}{\gamma}\right)^{2} \cdot \frac{\sigma_{d_{1}}{ }^{2}}{d_{1}{ }^{2}}
\end{aligned}
$$

Assuming that the error $\sigma_{d}$ and the relative errors $\sigma_{V} / V$ and $\sigma_{P} / P_{0}$ are the same for the measurements performed with target $n^{\circ} 1$ and $\operatorname{target} n^{\circ} 2$, we have:

$$
\sigma_{\gamma}{ }^{2}=\frac{1}{2 \Delta d^{2}} \cdot\left(\frac{\sigma_{V}{ }^{2}}{V^{2}}+\frac{{\sigma_{P_{0}}}^{2}}{P_{0}{ }^{2}}\right)+\frac{\gamma^{2}}{\Delta d^{2}} \cdot\left[\left(d_{1}+\frac{1}{\gamma}\right)^{2} \cdot \frac{\sigma_{d}{ }^{2}}{d_{1}{ }^{2}}+\left(d_{2}+\frac{1}{\gamma}\right)^{2} \cdot \frac{\sigma_{d}{ }^{2}}{d_{2}{ }^{2}}\right]
$$

Rearranging the terms, we obtain:

$$
\sigma_{\gamma}=\frac{1}{\Delta d} \cdot \sqrt{\left\{\frac{1}{2} \cdot\left(\frac{\sigma_{V}{ }^{2}}{V^{2}}+\frac{{\sigma_{P_{0}}}^{2}}{P_{0}{ }^{2}}\right)+\gamma^{2} \cdot\left[\left(d_{1}+\frac{1}{\gamma}\right)^{2} \cdot \frac{\sigma_{d}{ }^{2}}{d_{1}{ }^{2}}+\left(d_{2}+\frac{1}{\gamma}\right)^{2} \cdot \frac{\sigma_{d}{ }^{2}}{d_{2}{ }^{2}}\right]\right\}}
$$

Thus, it is evident that the error in the measurement of $\gamma$ is strongly affected by the distance between the two targets. For instance, in the case of laser system with transmitter/receiver parameters, $\sigma_{V} / V=5 \%$ and $\sigma_{P O} / P_{O}=2 \%$. Assuming $\sigma_{d}=1$ $\mathrm{m}, d_{1}=800 \mathrm{~m}, \Delta d=100 \mathrm{~m}, d_{2}=900 \mathrm{~m}, \gamma=7 \times 10^{-4} \mathrm{~m}^{-1}$, from Eq. (31) we obtain a relative measurement error $\sigma_{\gamma} / \gamma$ of about 54\%. Obviously, doubling the distance between the two targets (e.g, assuming $\Delta d=200 \mathrm{~m}$ and $d_{2}=1000 \mathrm{~m}$ ), the estimated relative error would be $27 \%$ (half of the previous case). Assuming that the laser platform and target coordinates can be determined with a $\sigma_{d} \leq 0.01$, we obtain:

$$
\begin{aligned}
& \frac{1}{2} \cdot\left(\frac{\sigma_{V}{ }^{2}}{V^{2}}+\frac{\sigma_{P_{o}}{ }^{2}}{P_{O}{ }^{2}}\right) \gg>\gamma^{2} \cdot\left[\left(d_{1}+\frac{1}{\gamma}\right)^{2} \cdot \frac{\sigma_{d}{ }^{2}}{d_{1}{ }^{2}}+\left(d_{2}+\frac{1}{\gamma}\right)^{2} \cdot \frac{\sigma_{d}{ }^{2}}{d_{2}{ }^{2}}\right] \\
& \sigma_{\gamma} \cong \frac{1}{\Delta d} \cdot \sqrt{\frac{1}{2} \cdot\left(\frac{\sigma_{V}{ }^{2}}{V^{2}}+\frac{\sigma_{P_{o}}{ }^{2}}{P_{o}{ }^{2}}\right)}
\end{aligned}
$$

Assuming $\Delta d=1000 \mathrm{~m}$, the estimated measurement error would be:

$$
\sigma_{\gamma} \cong \frac{1}{\Delta d} \cdot \sqrt{\frac{1}{2} \cdot\left(\frac{\sigma_{V}{ }^{2}}{V^{2}}+\frac{\sigma_{P_{o}}{ }^{2}}{P_{O}{ }^{2}}\right)}=3.81 \cdot 10^{-5} \mathrm{~m}^{-1}
$$

Since in general $\gamma>10^{-4} \mathrm{~m}^{-1}$, we obtain a maximum relative error $\sigma_{\gamma} / \gamma$ of about $4 \%$. 


\subsection{LTM-B Method}

A second method for atmospheric measurements by lasers (LTM-B) is depicted in Fig. 6.

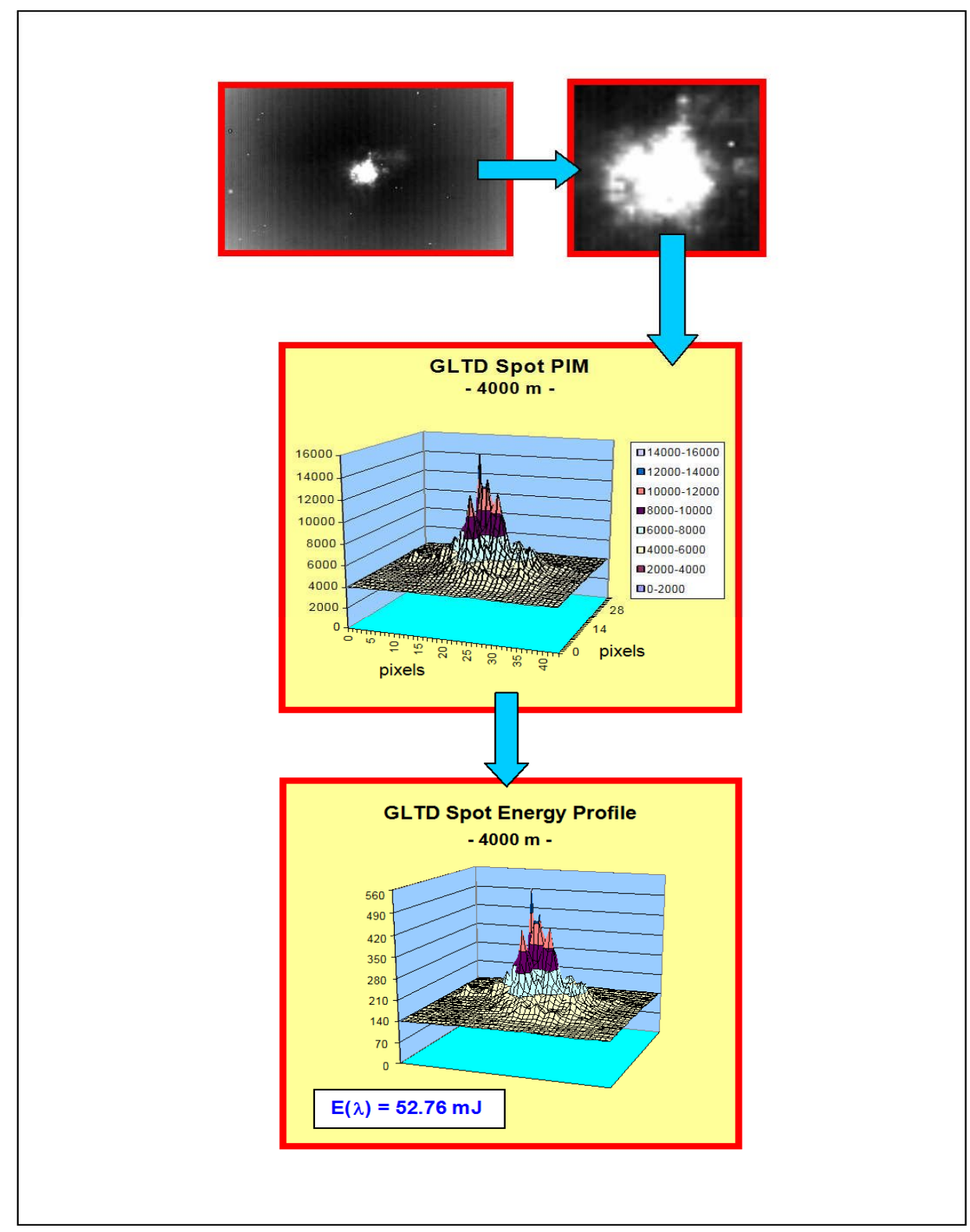

Figure 6. LTM-B Method.

In this case, pulse laser energy (transmitted from an aircraft, satellite, UAV, etc.) is measured directly on a reference target of known geometric and reflective characteristics ( $\rho$, BRDF, orientation, etc.), by using NIR cameras with associated image processing software (incorporating appropriate geometric algorithms and target reflectance data to perform radiance measurements in the focal plane). Also from this basic method, two Energy Measurement Techniques (EMT) were developed for non-calibrated (EMT-1) and calibrated (EMT-2) NIR cameras. For the case of non-calibrated IR cameras (EMT-1), the reference target has to be instrumented with suitable IR detectors (e.g., Pyroelectric Probes PEPs) with associated optics. The layout of an instrumented target surface used for some representative ground and flight trials measurements are shown in Fig. 7. 


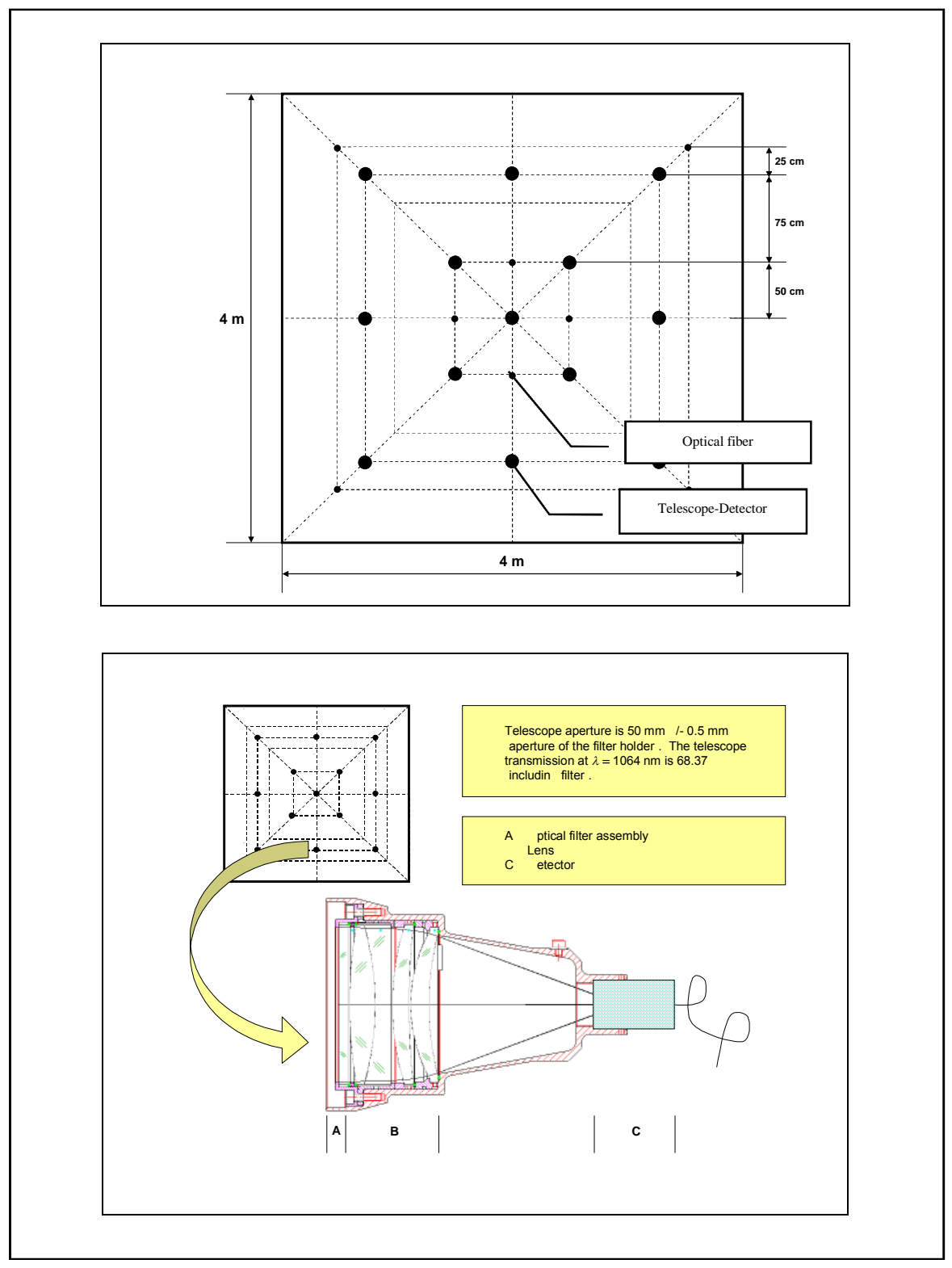

Figure 7. Target layout for LMT-B non-calibrated (EMT-1).

As an alternative to using instrumented targets, the IR cameras can be calibrated in a lab by adopting the setup shown in Fig. 8 (EMT-2). IR cameras employing photo-detectors are characterized by an output signal proportional to the incident IR energy. Particularly, in an IR camera employing a two-dimensional sensor matrix (i.e., Focal Plane Array - FPA) this is true for every single pixel. Therefore, from the numeric information associated to the image (i.e., Grey-scale Pixel Intensity Matrix - GPIM) it is possible to reconstruct the two-dimensional map of the energy irradiated by a target within the scene observed by the IR camera (integrated radiance in the camera spectral band). In the IR camera, the FPA analog signals are processed by the read-out electronic circuits, producing a digital output of the image (typically 12-bit Analog Digital Unit - ADU). Therefore, constructing a calibration curve for the Radiant Intensities (W/ $\mathrm{cm}^{2}$ sr) associated to the ADU Grey-scale values, and using dedicated image analysis software, it is possible to obtain the image Energy Pixel Intensity Matrix (EPIM) giving the energy associated to each pixel in the IR camera image. The linearity of the photodetector response allows accurate measurements in the camera dynamic range, with only a limited number of calibration 
data points. Furthermore, IR cameras featuring a variable integration time (selectable by the operator), give the opportunity of performing measurements in a linear regime within a wide interval of integrated radiance values, thus obtaining reliable measurements.

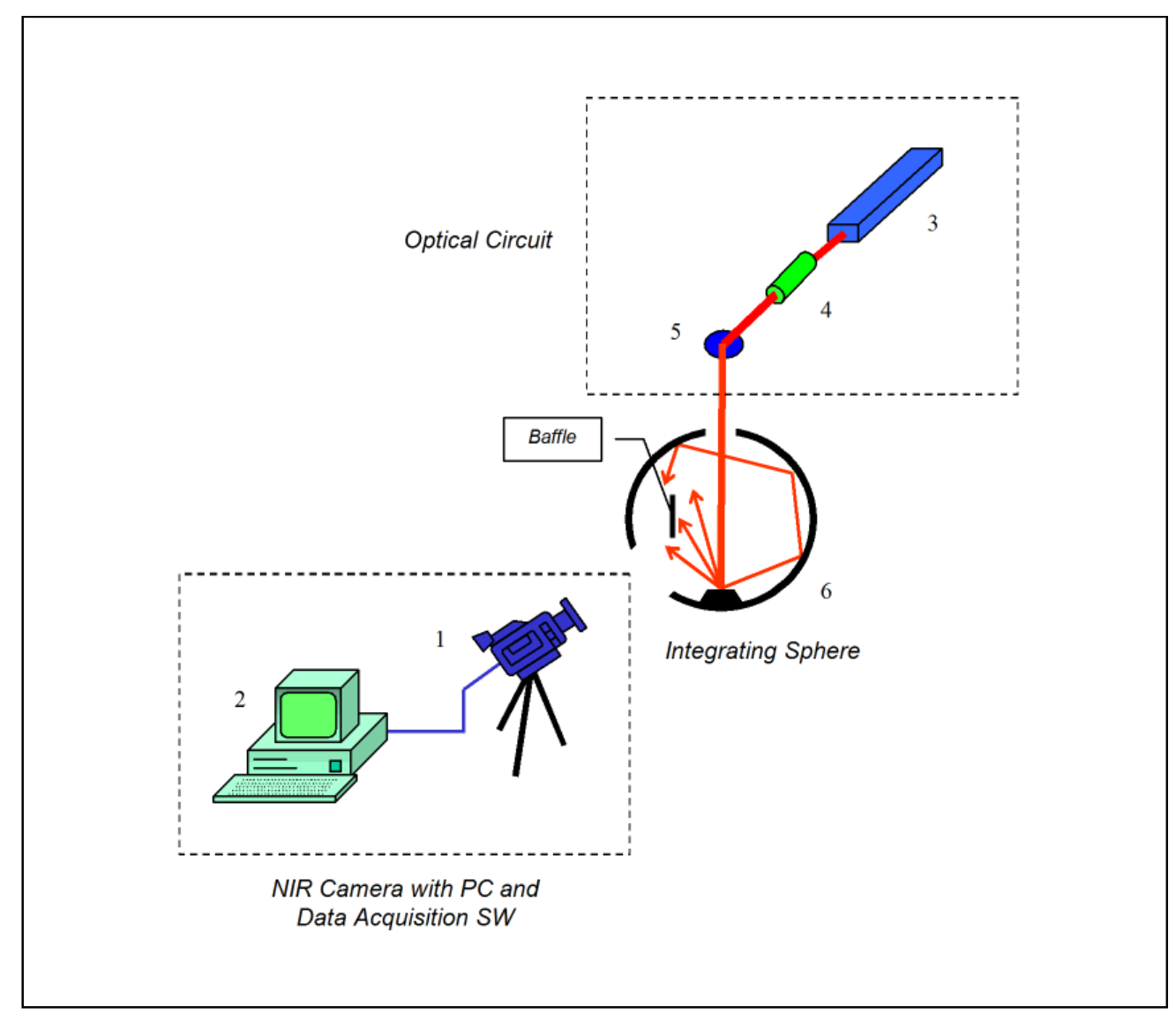

Figure 8. NIR camera calibration procedure (EMT-2).

Calibration allows determination of the ADU/Integrated Radiance Response Function (AIRF). The inverse of the AIRF is used by the image analysis software tool in order to obtain, directly as an image attribute, the values of integrated energy in the spectral band of the camera. For a photo-detector, the response of a single pixel in terms of ADU is:

$$
\mathrm{ADU}_{\mathrm{i}, \mathrm{j}} \propto \frac{\mathrm{A}}{4 \cdot \mathrm{f} \#^{2}+1} \cdot \mathrm{g} \cdot \mathrm{i}_{\text {time }} \cdot \int_{\lambda_{1}}^{\lambda_{2}} \tau_{\lambda} \eta \cdot \mathrm{E}_{\lambda} \mathrm{d} \lambda
$$

where $\lambda$ is wavelength, $\lambda_{1}$ and $\lambda_{2}$ are the limits of the camera spectral band (filtered), $\eta$ is the detector quantum efficiency (whose spectral distribution is typically constant), $E_{\lambda}$ is the spectral radiance, $\tau_{\lambda}$ is the optics transmittance, $A$ is the pixel area, $g$ is the gain of the read-out electronics, $f \#$ is the f-number of the optics and $i_{\text {time }}$ is the camera integration time. Therefore, the experimental parameters to be controlled during the calibration procedure are the integration time, the optics f-number and other settings of the NIR camera (e.g., the gain of the read-out electronics which may be selected by the operator). Fixing these parameters for a certain interval of integral radiance, it is possible to determine the AIRF of the camera by using an extended reference source. The function (calibration curve) so obtained, valid for the specific setup of the camera previously defined, is then used to determine the values of integral radiance to be used for reconstructing the radiant intensity map of the target. As an example, the spectral response (determined experimentally) of an NIR camera InGaAs sensor is shown in Fig. 9. 


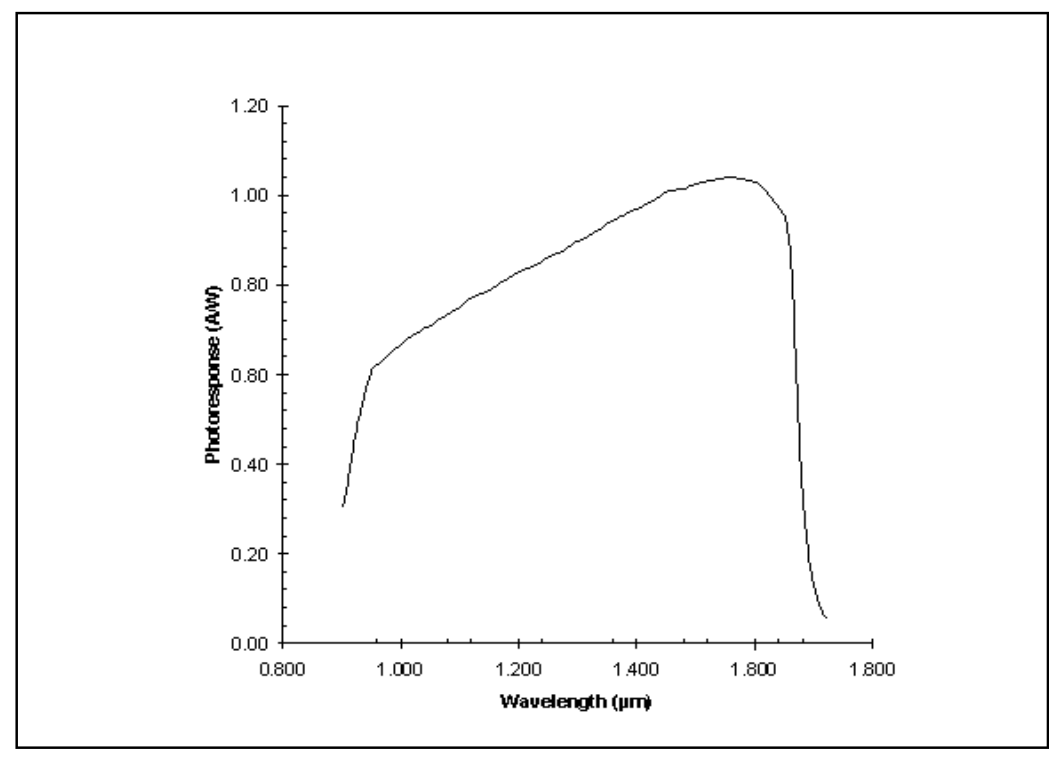

Figure 9. Spectral response of an InGaAs FPA.

The curve shows that the sensor output is a value of radiance integrated in the band $0.9-1.6 \mu \mathrm{m}$. This implies that, in order to perform measurements of the energy reflected by a target (with known reflectance characteristics) illuminated by a laser, it is necessary to reduce the spectral response of the camera by using a narrow band filter (centred on the laser wavelength), in order to eliminate the contributions of the background. The use of such a filter allows, using the same camera setup, accurate measurements of laser energy, independently from the ambient illumination, both in day and night conditions.

\section{EXPERIMENTAL RESULTS}

In this section we present some experimental results relative to some test activities performed using the proposed techniques (LTM-A and LTM-B, with both EMT-1 and EMT-2). Particularly, both ground and flight test activities results performed with laser systems operating in the NIR at $\lambda=1064 \mathrm{~nm}$ (Nd:YAG) and $\lambda=1550 \mathrm{~nm}$ (Erbium-fibre) are presented. This includes actual ground trials with high/low PRF systems, and flight trials performed with a pulsed airborne laser system installed on a TORNADO aircraft. During these test activities measurements were performed of horizontal and oblique/vertical path atmospheric transmission up to altitudes of 22,000 ft AGL, in a large variety of atmospheric conditions. This permitted to validate and, in some cases, also to improve the proposed extinction measurement techniques and the inversion algorithms for determination of the atmospheric chemical species and aerosol particles concentrations.

\subsection{Propagation Trials at $\lambda=1064 \mathrm{~nm}$}

Propagation trials at $\lambda=1064 \mathrm{~nm}$ were performed at the Air Force Flight Test Range in Sardinia (Italy) using a modular target and the laser system positioned along the target normal at a distance of $2.5 \mathrm{~km}, 4 \mathrm{~km}$ and $5.5 \mathrm{~km}$. The target Mean Sea Level (MSL) altitude was about $500 \mathrm{~m}$ and the maximum altitude difference between the laser transmitter and the target was about $140 \mathrm{~m}$ at a distance of $5.5 \mathrm{~km}$. The geometry of the $\lambda=1064 \mathrm{~nm}$ propagation tests performed at the range are shown in Fig. 10. 


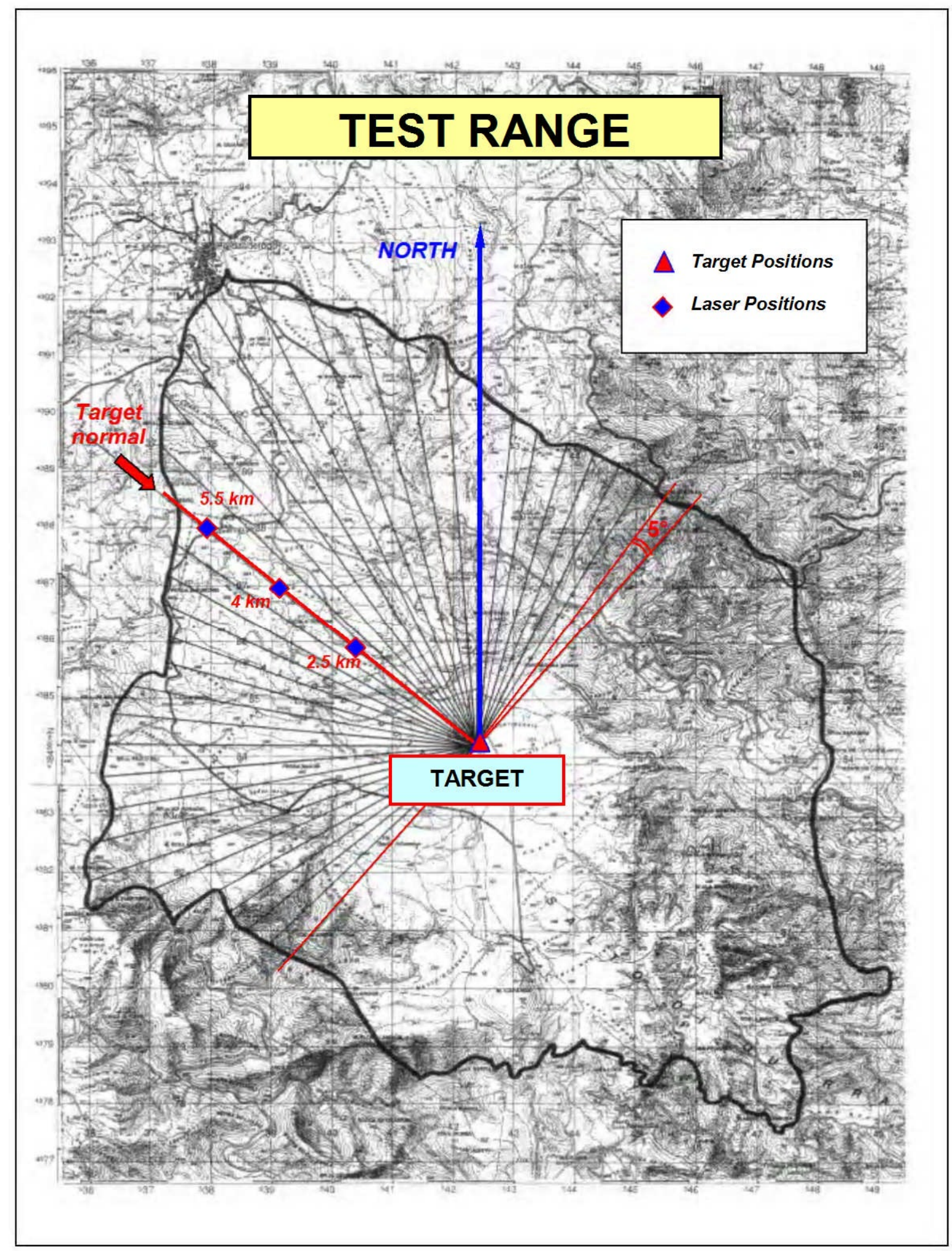

Figure 10. Geometry of atmospheric propagation measurements at $\lambda=1064 \mathrm{~nm}$. 
Table 11 shows the relevant data describing the meteorological conditions in which the atmospheric propagation measurements were performed (dry-air conditions). The various test cases have been grouped for classes of visibility and the corresponding International Visibility Code (IVC) classes are reported. When significant variations of $T$ and/or $R H$ were observed during the measurements, only the average values calculated in the relevant time intervals have been reported. The prevailing wind direction/intensity during the measurements is listed with respect to the laser to target slant-path (usual counter-clockwise convention). The values of the Turbulence Structure Constant $\left(C_{n}\right)$ were determined using the SCINTEC BLS900 laser scintillometer, with a measurement baseline of $5 \mathrm{~km}$ between transmitter and receiver (along the target normal).

Table 11. Meteorological data for dry-air propagation measurements at $\lambda=1064 \mathrm{~nm}$.

\begin{tabular}{|c|c|c|c|c|c|c|c|c|}
\hline Group & Case & $\begin{array}{c}V \\
(\mathrm{~km})\end{array}$ & $\begin{array}{l}R H \\
(\%)\end{array}$ & $\begin{array}{c}T \\
\left({ }^{\circ} \mathrm{C}\right)\end{array}$ & $C_{n}$ & Cloud & $\begin{array}{l}\text { Wind } \\
\text { (\%/kts) }\end{array}$ & IVC \\
\hline \multirow[t]{3}{*}{$I$} & $A$ & 2.5 & 82 & 24 & $6.77^{*} 10^{-8}$ & $6 / 8$ & $0 / 0$ & \multirow{3}{*}{ Haze } \\
\hline & $B$ & 3.0 & 85 & 15 & $1.80 * 10^{-8}$ & $5 / 8$ & $0 / 0$ & \\
\hline & $c$ & 3.5 & 76 & 23 & $9.86^{*} 10^{-7}$ & $7 / 8$ & $92 / 2$ & \\
\hline \multirow[t]{3}{*}{ II } & $A$ & 5 & 73 & 25 & $8.79^{*} 10^{-8}$ & $3 / 8$ & $0 / 0$ & \multirow{6}{*}{ Light Haze } \\
\hline & $B$ & 6.0 & 66 & 27 & $6.67^{*} 10^{-8}$ & $4 / 8$ & $237 / 3$ & \\
\hline & $c$ & 7.0 & 68 & 7 & $1.82^{*} 10^{-7}$ & $7 / 8$ & $0 / 0$ & \\
\hline \multirow[t]{3}{*}{ III } & $A$ & 8.0 & 67 & 24 & $8.96^{*} 10^{-8}$ & $3 / 8$ & $0 / 0$ & \\
\hline & $B$ & 8.5 & 58 & 28 & $6.70 * 10^{-8}$ & $3 / 8$ & $120 / 5$ & \\
\hline & $c$ & 9.0 & 64 & 30 & $2.92 * 10^{-7}$ & $4 / 8$ & $0 / 0$ & \\
\hline \multirow[t]{4}{*}{ IV } & $A$ & 10.0 & 51 & 20 & $7.16^{*} 10^{-7}$ & $2 / 8$ & $40 / 6$ & \multirow{7}{*}{ Clear } \\
\hline & $B$ & 10.5 & 58 & 28 & $1.87^{*} 10^{-7}$ & $1 / 8$ & $95 / 12$ & \\
\hline & $c$ & 11 & 51 & 18 & $6.39 * 10^{-8}$ & $2 / 8$ & $120 / 8$ & \\
\hline & $D$ & 12.5 & 48 & 32 & $8.56^{*} 10^{-7}$ & $3 / 8$ & $0 / 0$ & \\
\hline \multirow[t]{3}{*}{$V$} & $A$ & 14.5 & 52 & 18 & $1.09 * 10^{-8}$ & $2 / 8$ & $22 / 4$ & \\
\hline & $B$ & 15.0 & 44 & 32 & $4.87^{*} 10^{-7}$ & $3 / 8$ & $320 / 7$ & \\
\hline & $c$ & 18.5 & 56 & 24 & $7.98 * 10^{-8}$ & $0 / 8$ & $35 / 5$ & \\
\hline \multirow[t]{4}{*}{ VI } & $A$ & 20.5 & 40 & 31 & $4.49 * 10^{-8}$ & $0 / 8$ & $0 / 0$ & \multirow{4}{*}{ Very Clear } \\
\hline & B & 22.5 & 41 & 35 & $5.87^{*} 10^{-7}$ & $2 / 8$ & $25 / 8$ & \\
\hline & $c$ & 25.0 & 47 & 35 & $7.56 * 10^{-7}$ & $1 / 8$ & $125 / 10$ & \\
\hline & $D$ & 34.0 & 35 & 32 & $6.84^{*} 10^{-8}$ & $0 / 8$ & $15 / 7$ & \\
\hline
\end{tabular}

For each case listed in Table 11, a minimum of 25 energy measurements were performed (samples of 25 to 50 laser spot measurements were used) using at least two of the laser system locations shown in Fig. 11. Dry-air extinction tests were performed in all meteorological conditions listed in Table 11 only with a system to target slant-range (SR) of $2.5 \mathrm{~km}$. With SR $=4 \mathrm{~km}$ and $\mathrm{SR}=5.5 \mathrm{~km}$, extinction tests were performed in a representative sub-set of dry-air meteorological conditions. Rain extinction tests were not performed at $\lambda=1064 \mathrm{~nm}$. Transmittance and extinction coefficient values relative to the various test cases (i.e., meteorological conditions listed in Tables 11), calculated using the ESLM model with $\mathrm{SR}=1 \mathrm{~km}$, are listed in Table 12 . 
Table 12. Calculated extinction coefficients for dry-air conditions $(\mathrm{SR}=2.5 \mathrm{~km})$.

\begin{tabular}{|c|c|c|c|c|}
\hline Group & Case & IVC Categ. & Model $\tau$ & Model $\gamma\left(\mathrm{km}^{-1}\right)$ \\
\hline \multirow[t]{3}{*}{$I$} & A & \multirow{3}{*}{ Haze } & 0.077 & 1.025 \\
\hline & B & & 0.127 & 0,824 \\
\hline & C & & 0.168 & 0,714 \\
\hline \multirow[t]{3}{*}{ II } & A & \multirow{6}{*}{$\begin{array}{l}\text { Light } \\
\text { Haze }\end{array}$} & 0.287 & 0,500 \\
\hline & B & & 0.351 & 0,419 \\
\hline & C & & 0.448 & 0,321 \\
\hline \multirow[t]{3}{*}{ III } & A & & 0.455 & 0,315 \\
\hline & B & & 0.470 & 0,302 \\
\hline & C & & 0.476 & 0,297 \\
\hline \multirow[t]{4}{*}{ IV } & A & \multirow{7}{*}{ Clear } & 0.549 & 0,240 \\
\hline & B & & 0.532 & 0,252 \\
\hline & C & & 0.583 & 0,216 \\
\hline & D & & 0.575 & 0,221 \\
\hline \multirow[t]{3}{*}{$v$} & A & & 0.652 & 0,171 \\
\hline & B & & 0.622 & 0,190 \\
\hline & C & & 0.675 & 0,157 \\
\hline \multirow[t]{4}{*}{ VI } & A & \multirow{4}{*}{$\begin{array}{l}\text { Very } \\
\text { Clear }\end{array}$} & 0.688 & 0,149 \\
\hline & B & & 0.684 & 0,152 \\
\hline & C & & 0.687 & 0,150 \\
\hline & D & & 0.755 & 0,112 \\
\hline
\end{tabular}

The extinction coefficients in Table 7 were computed from model transmittances, using the simple equation:

$$
\gamma=-\frac{\ln \tau}{S R}
$$

However, it is important to observe that, although the ESLM model provides independent estimates of both absorptive transmittance $\left(\tau_{a i}\right)$ and scattering transmittance $\left(\tau_{s i}\right)$, only the scattering contribution to the extinction coefficient $\left(\gamma_{s i}\right)$ is independent of range. In fact, the precipitable water in $\mathrm{mm}$ is $w=S R \cdot A H$ (where $S R$ is the slant-range in $\mathrm{km}$ and $A H$ is the absolute humidity in $\mathrm{g} / \mathrm{m}^{3}$ ), and $A H$ is approximated by:

$$
A H=1322.8 \frac{R H}{T} \exp \left[\frac{25.22(T-273.16)}{T}-5.31 \ln \left(\frac{T}{273.16}\right)\right]
$$

According to the ESLM model, as $w<54$ for all cases in Table 6, the absorptive transmittance is given by:

$$
\tau_{a i}=e^{-0.0363 \cdot \sqrt{w}}
$$

Therefore, in this case, the absorptive extinction coefficient $\left(\gamma_{a i}\right)$ is given by:

$$
\gamma_{a i}=0.0363 \cdot A H \cdot \frac{1}{\sqrt{S R}}
$$


where the SR dependency of $\gamma_{a i}$ is evident (obviously, for SR $=1 \mathrm{~km}$ the model $\gamma_{a i}$ becomes a function of $A H$ only). For instance, with $S R=10 \mathrm{~km}$, the model $\gamma_{a i}$ is about one third of the value calculated, with the same $R H$ and $T$ conditions, with SR $=1 \mathrm{~km}$. In other words, the ESLM empirical model implies a range dependency of the extinction coefficient, which prevents a direct comparisons of the experimental $\gamma$ values found at a certain SR with $\gamma$ values predicted or measured at a different SR. Although this appears as a limitation of the ESLM model for practical applications, for all SR considered we determined from NIR-camera energy measurements and $\gamma$ using Eq. (74), and compared the calculated values with the experimental results. Therefore, for each SR, different sets of corrections were computed simply by comparing the predicted ESLM $\tau$ and $\gamma$ values with the experimental data. Since the initial phases of the test activity, data collected in various meteorological conditions and with various laser slant-paths, demonstrated moderate discrepancies between the extinction measurements performed with EMT-1 and EMT-2 (i.e., 8\% maximum difference). Furthermore, using the two techniques, no significant correlation was observed between the differences in the measurements and the lengths of the laser slant-paths used to gather the experimental data. Table 13 shows the results of transmittance measurements performed using the EMT-2 technique for a laser slant-path of $2.5 \mathrm{~km}$, compared with ESLM model computations.

Table 13. Transmittance data and ESLM model corrections $(\lambda=1064 \mathrm{~nm}-\mathrm{SR}=2.5 \mathrm{~km})$.

\begin{tabular}{|c|c|c|c|c|c|c|c|}
\hline Group & Case & $\begin{array}{c}\text { IVC } \\
\text { Categ. }\end{array}$ & Experim. $\tau$ & Model $\tau$ & $\begin{array}{c}\text { Error } \\
\text { (\%) }\end{array}$ & $\begin{array}{l}\text { Group } \\
\text { Corr. }\end{array}$ & $\begin{array}{c}\text { IVC Cat. } \\
\text { Corr. }\end{array}$ \\
\hline \multirow[t]{3}{*}{$I$} & A & \multirow{3}{*}{ Haze } & 0.088 & 0.077 & 14.91 & \multirow[t]{3}{*}{1.149} & \multirow[t]{3}{*}{1.149} \\
\hline & B & & 0.146 & 0.127 & 15.15 & & \\
\hline & C & & 0.192 & 0.168 & 14.57 & & \\
\hline \multirow[t]{3}{*}{ II } & A & \multirow{6}{*}{$\begin{array}{l}\text { Light } \\
\text { Haze }\end{array}$} & 0.331 & 0.287 & 15.46 & \multirow[t]{3}{*}{1.150} & \multirow[t]{6}{*}{1.141} \\
\hline & B & & 0.406 & 0.351 & 15.69 & & \\
\hline & C & & 0.510 & 0.448 & 13.80 & & \\
\hline \multirow[t]{3}{*}{ III } & A & & 0.513 & 0.455 & 12.80 & \multirow[t]{3}{*}{1.131} & \\
\hline & B & & 0.537 & 0.470 & 14.20 & & \\
\hline & C & & 0.535 & 0.476 & 12.40 & & \\
\hline \multirow[t]{4}{*}{ IV } & A & \multirow{7}{*}{ Clear } & 0.630 & 0.549 & 14.58 & \multirow[t]{4}{*}{1.140} & \multirow[t]{7}{*}{1.132} \\
\hline & B & & 0.597 & 0.532 & 12.17 & & \\
\hline & C & & 0.666 & 0.583 & 14.23 & & \\
\hline & D & & 0.662 & 0.575 & 15.14 & & \\
\hline \multirow[t]{3}{*}{$v$} & A & & 0.737 & 0.652 & 13.00 & \multirow[t]{3}{*}{1.125} & \\
\hline & B & & 0.704 & 0.622 & 13.20 & & \\
\hline & C & & 0.751 & 0.675 & 11.20 & & \\
\hline \multirow[t]{4}{*}{ VI } & A & \multirow{4}{*}{$\begin{array}{l}\text { Very } \\
\text { Clear }\end{array}$} & 0.765 & 0.688 & 11.14 & \multirow[t]{4}{*}{1.113} & \multirow[t]{4}{*}{1.113} \\
\hline & B & & 0.767 & 0.684 & 12.16 & & \\
\hline & C & & 0.760 & 0.687 & 10.52 & & \\
\hline & D & & 0.840 & 0.755 & 11.27 & & \\
\hline
\end{tabular}

In all cases, the measured transmittance values (i.e., average of 25-50 spot measurements) were greater than the values computed using the ESLM model. The observed differences between measured and ESLM transmittances varied between $10.52 \%$ and $16.64 \%$. The ESLM transmittance model corrections computed for each group and for each IVC category are also listed in Table 14. It is evident, looking at the results in Table 13 and at their graphical representation 
in Fig. 11, that the difference between predicted and measured transmittance decreases significantly as atmospheric visibility increases.

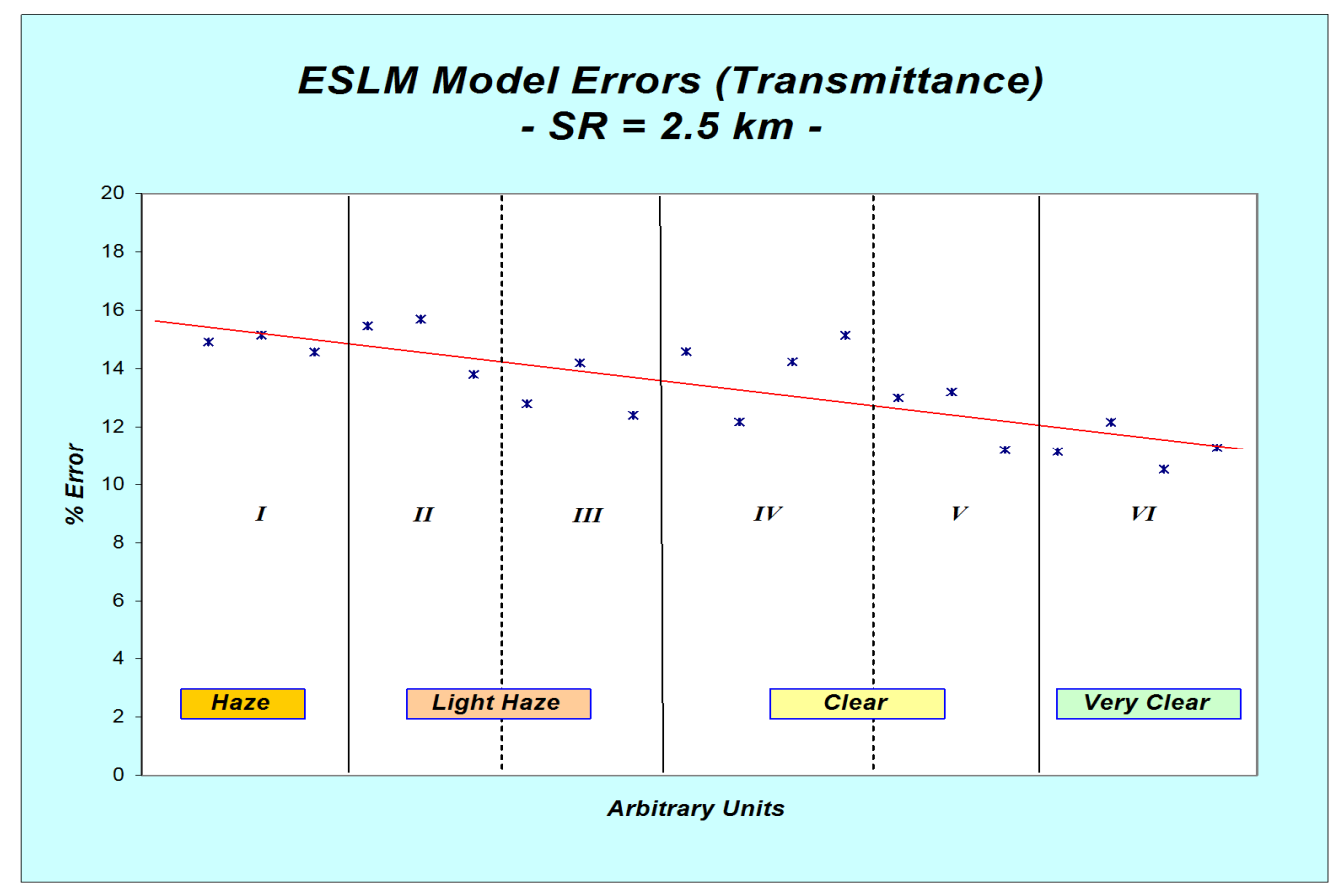

Figure 11. ESLM model errors (transmittance) for $\mathrm{SR}=2.5 \mathrm{~km}$.

Experimental data and error computations relative to the measurements performed with SR $=4 \mathrm{~km}$ and $\mathrm{SR}=5.5 \mathrm{~km}$ are presented in Tables 14 and 15. Although with these SR's measurements were not performed in all meteorological conditions listed in Table 11, looking at the available data it appears evident that the ESLM model errors are comparable with the errors computed for $\mathrm{SR}=2.5 \mathrm{~km}$.

Table 14. Transmittance data and ESLM model corrections $(\lambda=1064 \mathrm{~nm}-\mathrm{SR}=4 \mathrm{~km})$.

\begin{tabular}{|c|c|c|c|c|c|c|c|}
\hline Group & Case & $\begin{array}{c}\text { IVC } \\
\text { Categ. }\end{array}$ & Experim. $\tau$ & Model $\tau$ & $\begin{array}{c}\text { Error } \\
(\%)\end{array}$ & $\begin{array}{c}\text { Group } \\
\text { Corr. }\end{array}$ & $\begin{array}{c}\text { IVC Cat. } \\
\text { Corr. }\end{array}$ \\
\hline \multirow[t]{2}{*}{ II } & A & \multirow{4}{*}{$\begin{array}{l}\text { Light } \\
\text { Haze }\end{array}$} & 0.179 & 0.147 & 17.88 & \multirow[t]{2}{*}{1.214} & \multirow[t]{4}{*}{1.213} \\
\hline & C & & 0.351 & 0.290 & 17.39 & & \\
\hline \multirow[t]{2}{*}{ III } & B & & 0.384 & 0.323 & 15.92 & \multirow[t]{2}{*}{1.212} & \\
\hline & c & & 0.410 & 0.332 & 18.96 & & \\
\hline \multirow[t]{2}{*}{ IV } & A & \multirow{3}{*}{ Clear } & 0.489 & 0.406 & 17.03 & \multirow[t]{2}{*}{1.192} & \multirow[t]{3}{*}{1.168} \\
\hline & B & & 0.463 & 0.393 & 15.18 & & \\
\hline$v$ & C & & 0.652 & 0.570 & 12.52 & 1.143 & \\
\hline$V I$ & A & $\begin{array}{l}\text { Very } \\
\text { Clear }\end{array}$ & 0.681 & 0.590 & 13.34 & 1.154 & 1.154 \\
\hline
\end{tabular}


Table 15. Transmittance data and ESLM model corrections $(\lambda=1064 \mathrm{~nm}-\mathrm{SR}=5.5 \mathrm{~km})$.

\begin{tabular}{|c|c|c|c|c|c|c|c|}
\hline Group & Case & $\begin{array}{c}\text { IVC } \\
\text { Categ. }\end{array}$ & Experim. $\tau$ & Model $\tau$ & $\begin{array}{c}\text { Error } \\
(\%)\end{array}$ & $\begin{array}{c}\text { Group } \\
\text { Corr. }\end{array}$ & $\begin{array}{c}\text { IVC Cat. } \\
\text { Corr. }\end{array}$ \\
\hline \multirow[t]{2}{*}{ II } & B & \multirow{4}{*}{$\begin{array}{l}\text { Light } \\
\text { Haze }\end{array}$} & 0.143 & 0.118 & 20.78 & \multirow[t]{2}{*}{1.252} & \multirow[t]{4}{*}{1.280} \\
\hline & c & & 0.233 & 0.188 & 19.48 & & \\
\hline \multirow[t]{2}{*}{ III } & B & & 0.285 & 0.224 & 21.48 & \multirow[t]{2}{*}{1.308} & \\
\hline & C & & 0.314 & 0.234 & 25.45 & & \\
\hline \multirow[t]{2}{*}{ IV } & A & \multirow{4}{*}{ Clear } & 0.381 & 0.303 & 20.42 & \multirow[t]{2}{*}{1.259} & \multirow[t]{4}{*}{1.255} \\
\hline & B & & 0.371 & 0.294 & 20.69 & & \\
\hline \multirow[t]{2}{*}{$v$} & A & & 0.537 & 0.439 & 18.30 & \multirow[t]{2}{*}{1.252} & \\
\hline & B & & 0.527 & 0.412 & 21.82 & & \\
\hline \multirow[t]{2}{*}{$V I$} & B & \multirow{2}{*}{$\begin{array}{l}\text { Very } \\
\text { Clear }\end{array}$} & 0.611 & 0.512 & 16.18 & \multirow[t]{2}{*}{1.181} & \multirow[t]{2}{*}{1.181} \\
\hline & D & & 0.726 & 0.621 & 14.41 & & \\
\hline
\end{tabular}

The ESLM model errors for computing $\gamma$, relative to the various test cases with SR $=2.5 \mathrm{~km}$ are shown in Fig. 12 . The error trends were not significantly affected by the system to target SR and, in all cases, the ESLM model always overestimated the extinction coefficient (i.e., under-estimated transmittance). Therefore, the experimental results are not in contrast with the $1 / \sqrt{S R}$ dependency of $\gamma_{a i}$ implied in the ESLM empirical model. The under estimation of $\tau$ can be explained observing that the ESLM model is a two components model (i.e., scattering transmittance $\tau_{s i}$ and absorptive transmittance $\tau_{a i}$ ) whose empiric equations were derived from independent scattering and absorption measurements, in which either absorption or scattering were neglected due to the particular test conditions. On the other hand, the effects of turbulence and other linear and non-linear propagation phenomena not included in the ESLM model, did not seem to significantly affect the energy measurements performed using EMT-2 and the ELOP-PLD laser system in the specified test conditions.

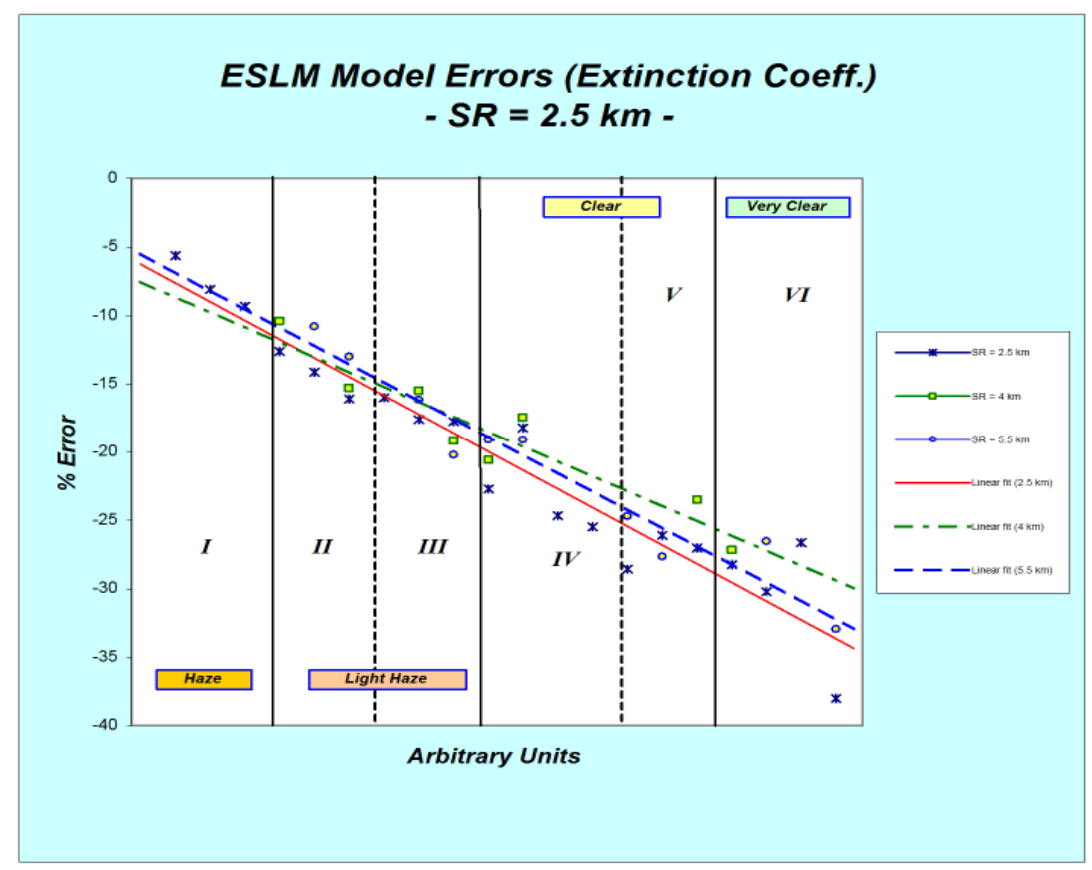

Figure 12. ESLM model errors for computation of $\gamma(\lambda=1064 \mathrm{~nm}-\mathrm{SR}=2.5 \mathrm{~km})$. 


\subsection{Propagation Tests at $\lambda=1550 \mathrm{~nm}$}

Propagation tests at $\lambda=1550 \mathrm{~nm}$ were performed using EMT-3, adopting the test setup illustrated in Fig. 6 with $\mathrm{D} 1=1500 \mathrm{~m}$ and $\mathrm{D} 2=500 \mathrm{~m}$. The parameters describing the meteorological conditions during the tests are listed in the Tables 16 and 17.

Table 16. Meteorological data for dry-air propagation measurements at $\lambda=1550 \mathrm{~nm}$.

\begin{tabular}{|c|c|c|c|c|c|c|c|c|}
\hline Group & Case & $\begin{array}{c}V \\
(\mathrm{~km})\end{array}$ & $\begin{array}{l}R H \\
\text { (\%) }\end{array}$ & $\begin{array}{c}T \\
\left({ }^{\circ} \mathrm{C}\right)\end{array}$ & $C_{n}$ & Cloud & $\begin{array}{l}\text { Wind } \\
\text { (\%/kts) }\end{array}$ & $I V C$ \\
\hline \multirow[t]{2}{*}{1} & $a$ & 3.0 & 82 & 25 & $7.45^{\star} 10^{-8}$ & $5 / 8$ & $92 / 8$ & \multirow{2}{*}{ Haze } \\
\hline & $b$ & 4.0 & 85 & 21 & $4.49^{*} 10^{-8}$ & $3 / 8$ & $95 / 2$ & \\
\hline \multirow[t]{3}{*}{2} & $a$ & 7.0 & 78 & 22 & $5.27^{\star} 10^{-8}$ & $5 / 8$ & $0 / 0$ & \multirow{3}{*}{ Light Haze } \\
\hline & $b$ & 8.0 & 67 & 25 & $7.30^{*} 10^{-7}$ & $2 / 8$ & $120 / 5$ & \\
\hline & $c$ & 9.0 & 72 & 29 & $2.65^{\star} 10^{-8}$ & $4 / 8$ & $45 / 8$ & \\
\hline \multirow[t]{4}{*}{3} & $a$ & 12.0 & 61 & 23 & $3.15^{\star} 10^{-8}$ & $3 / 8$ & $0 / 0$ & \multirow{4}{*}{ Clear } \\
\hline & $b$ & 15.5 & 49 & 31 & $5.90^{*} 10^{-8}$ & $0 / 8$ & $0 / 0$ & \\
\hline & $c$ & 18.0 & 55 & 28 & $7.66^{*} 10^{-7}$ & $0 / 8$ & $70 / 2$ & \\
\hline & $d$ & 20.0 & 57 & 30 & $5.23^{*} 10^{-7}$ & $2 / 8$ & $54 / 11$ & \\
\hline \multirow[t]{3}{*}{4} & $a$ & 22.5 & 52 & 31 & $5.80^{*} 10^{-7}$ & $0 / 8$ & $0 / 0$ & \multirow{3}{*}{ Very Clear } \\
\hline & $b$ & 24.0 & 44 & 35 & $4.65^{\star} 10^{-7}$ & $0 / 8$ & $130 / 6$ & \\
\hline & $c$ & 28.0 & 57 & 35 & $6.40^{*} 10^{-8}$ & $2 / 8$ & $46 / 7$ & \\
\hline
\end{tabular}

Table 17. Meteorological data for propagation measurements with rain at $\lambda=1550 \mathrm{~nm}$.

\begin{tabular}{|c|c|c|c|c|c|c|c|c|}
\hline Group & Case & $\begin{array}{c}\boldsymbol{V} \\
(\mathbf{k m})\end{array}$ & $\begin{array}{c}\boldsymbol{R H} \\
(\%)\end{array}$ & $\begin{array}{c}\boldsymbol{T} \\
\left({ }^{\circ} \mathbf{C}\right)\end{array}$ & $\boldsymbol{C}_{\boldsymbol{n}}$ & $\begin{array}{c}\text { Wind } \\
(\% / \mathbf{k t s})\end{array}$ & $\begin{array}{c}\text { Rainfall } \\
(\mathbf{c m} / \mathbf{h r})\end{array}$ & Type of Rain \\
\hline \multirow{2}{*}{5} & $\boldsymbol{a}$ & 3.0 & 100 & 10 & $3.22^{\star} 10^{-7}$ & $23 / 4$ & 2.10 & Heavy rain \\
\cline { 2 - 9 } & $\boldsymbol{b}$ & 5.0 & 90 & 12 & $5.90^{\star} 10^{-7}$ & $122 / 10$ & 1.45 & Med. Rain \\
\cline { 2 - 9 } & $\boldsymbol{c}$ & 6.0 & 90 & 18 & $8.12^{\star} 10^{-8}$ & $15 / 5$ & 0.30 & Light rain \\
\hline
\end{tabular}

The extinction coefficients calculated, for each case listed in the Tables 16 and 17, using the ESLM model, are listed in the Tables 18 and 19. 
Table 18. Calculated extinction coefficients for dry-air.

\begin{tabular}{|c|c|c|c|}
\hline Group & Case & IVC & Model $\gamma\left(\mathrm{km}^{-1}\right)$ \\
\hline 1 & $\begin{array}{l}a \\
b\end{array}$ & Haze & $\begin{array}{l}1.082 \\
0.890\end{array}$ \\
\hline 2 & $\begin{array}{l}a \\
b \\
c\end{array}$ & Light Haze & $\begin{array}{l}0.689 \\
0.661 \\
0.671\end{array}$ \\
\hline 3 & $\begin{array}{l}a \\
b \\
c \\
d\end{array}$ & Clear & $\begin{array}{l}0.573 \\
0.572 \\
0.556 \\
0.565\end{array}$ \\
\hline 4 & $\begin{array}{l}a \\
b \\
c\end{array}$ & Very Clear & $\begin{array}{l}0.555 \\
0.556 \\
0.579\end{array}$ \\
\hline
\end{tabular}

Table 19. Calculated extinction coefficients for rain.

\begin{tabular}{|c|c|c|c|}
\hline Group & Case & Type of Rain & Model $\gamma\left(\mathbf{k m}^{-\mathbf{1}}\right)$ \\
\hline \multirow{2}{*}{5} & $\boldsymbol{a}$ & Heavy rain & 2.944 \\
\cline { 2 - 4 } & $\boldsymbol{b}$ & Med. rain & 2,429 \\
\cline { 2 - 4 } & $\boldsymbol{c}$ & Light rain & 1,231 \\
\hline
\end{tabular}

The ESLM extinction coefficients in the Tables 18 and 19 were computed from model transmittances using the equation $\gamma=-\ln \tau / S R$ with $S R=1 \mathrm{~km}$. Experimental data and ESLM model errors relative to the measurements performed in both dry and rainy conditions are presented in the Tables 20 and 21. 
Table 20. Dry-air experimental data and ESLM model corrections $(\lambda=1550 \mathrm{~nm})$.

\begin{tabular}{|c|c|c|c|c|c|c|c|}
\hline Group & Case & $I V C$ & Model $\gamma$ & Exper. $\gamma$ & Error \% & Case Corr. & $\begin{array}{c}\text { IVC Cat. } \\
\text { Corr. }\end{array}$ \\
\hline \multirow[t]{2}{*}{1} & $a$ & \multirow{2}{*}{ Haze } & 1.082 & 0.816 & -24.56 & 0.754 & 0.745 \\
\hline & $b$ & & 0.890 & 0.655 & -26.43 & 0.736 & \\
\hline \multirow[t]{3}{*}{2} & $a$ & \multirow{3}{*}{ Light Haze } & 0.689 & 0.446 & $-35,20$ & 0.648 & 0.647 \\
\hline & $b$ & & 0.661 & 0.479 & $-27,58$ & 0.724 & \\
\hline & $c$ & & 0.671 & 0.381 & $-43,27$ & 0.567 & \\
\hline \multirow[t]{4}{*}{3} & $a$ & \multirow{4}{*}{ Clear } & 0.573 & 0.332 & $-42,10$ & 0.579 & 0.584 \\
\hline & $b$ & & 0.572 & 0.382 & $-33,30$ & 0.667 & \\
\hline & $c$ & & 0.556 & 0.350 & $-37,10$ & 0.629 & \\
\hline & $d$ & & 0.565 & 0.261 & $-53,80$ & 0.462 & \\
\hline \multirow[t]{3}{*}{4} & $a$ & \multirow{3}{*}{ Very Clear } & 0.555 & 0.324 & $-41,60$ & 0.584 & 0.601 \\
\hline & $b$ & & 0.556 & 0.354 & $-36,30$ & 0.637 & \\
\hline & $c$ & & 0.579 & 0.337 & $-41,67$ & 0.583 & \\
\hline
\end{tabular}

Table 21. Rain experimental data and ESLM model corrections $(\lambda=1550 \mathrm{~nm})$.

\begin{tabular}{|c|c|c|c|c|c|c|}
\hline \multirow{2}{*}{ Group } & Case & Type of Rain & Model $\gamma$ & Exper. $\gamma$ & Error \% & Case Corr. \\
\hline \multirow{2}{*}{5} & $\boldsymbol{a}$ & Heavy rain & 2.596 & 2.266 & -12.70 & 0.873 \\
\cline { 2 - 7 } & $\boldsymbol{b}$ & Med. rain & 2.080 & 2.006 & -3.56 & 0.964 \\
\cline { 2 - 7 } & C & Light rain & 0.864 & 0.729 & -15.67 & 0.843 \\
\hline
\end{tabular}

It is evident that, also at $\lambda=1550 \mathrm{~nm}$, there is a considerable difference between the experimental data and the ESLM model results. Again, the over estimation of $\gamma$ can be explained observing that the ESLM model is a two components model whose empiric equations were derived from independent scattering and absorption measurements, in which either absorption or scattering were neglected due to the particular test conditions. Furthermore, as the ESLM model uses different sets of equations for modelling absorption at $\lambda=1064 \mathrm{~nm}$ and $\lambda=1550 \mathrm{~nm}$, and slightly different parameters in the equations for modelling atmospheric scattering at the two wavelengths, remarkable differences were observed between the results obtained at $\lambda=1064 \mathrm{~nm}$ and $\lambda=1550 \mathrm{~nm}$. The differences in the overall (scattering plus absorption) transmittances and extinction coefficients, computed for a transmission path of $1 \mathrm{~km}$ and the same set of meteorological parameters listed in Table 18 (dry-air), are shown in Fig. 13. The greater contribution to the observed differences was due to absorptive extinction, which for $\lambda=1550 \mathrm{~nm}$ and $w>1.1$, was modelled as:

$$
\gamma_{a i}=-\frac{\ln \left(0.802 \cdot \frac{1.1}{w}\right)^{0.111}}{S R}
$$




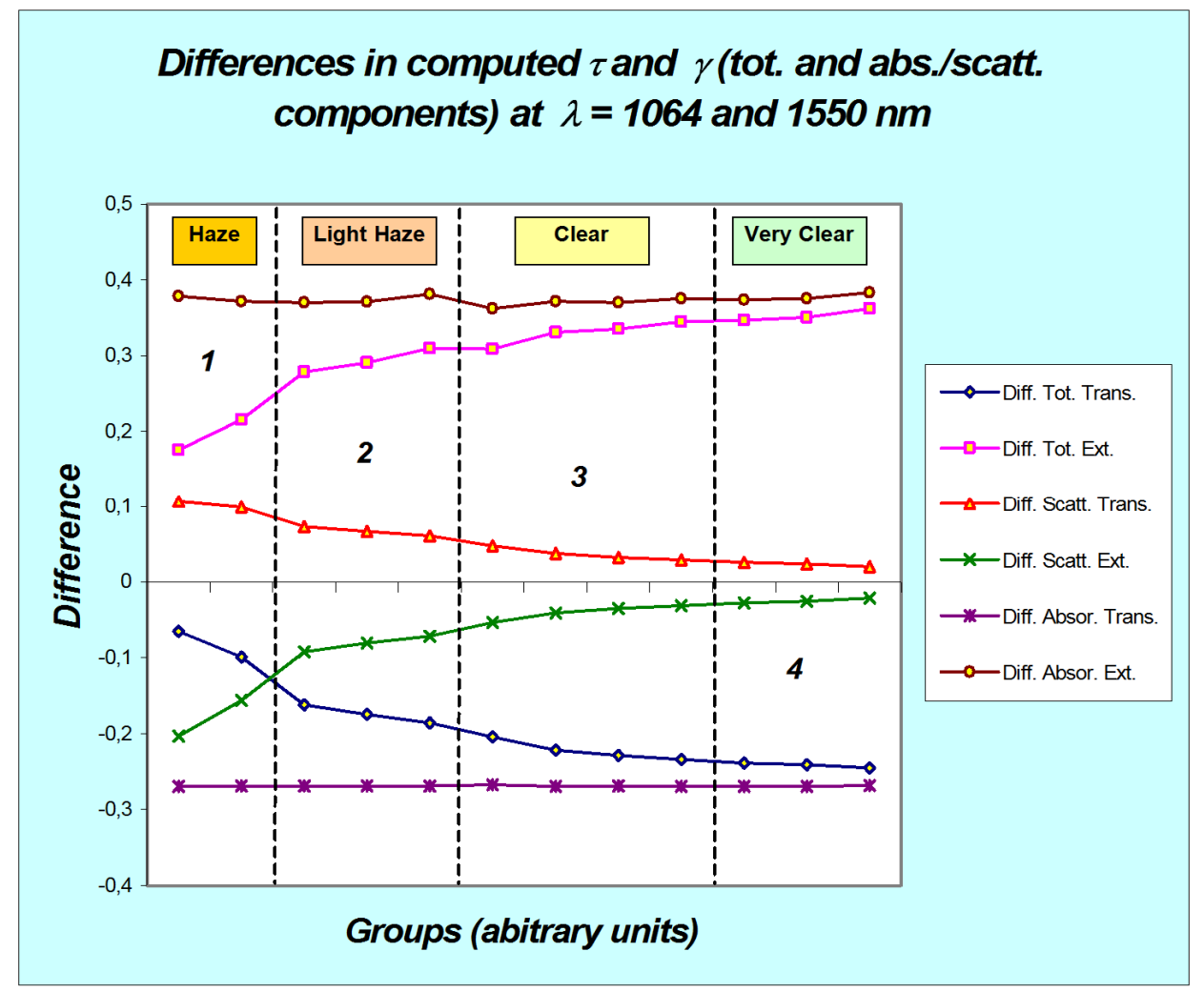

Figure 13. Differences in $\tau$ and $\gamma$ (total and absorptive/scattering components) computed with the ESLM model for $\lambda=1064 \mathrm{~nm}$ and $\lambda=1550 \mathrm{~nm}$.

On the other hand, the ESLM model for rainy conditions fitted reasonably well the experimental data, with transmittance computation errors not exceeding $15.67 \%$ (light rain case).

\subsection{Flight Trials}

Flight test activities were performed using the infrared version of the THOMSON Convertible Laser Designation Pod (CLDP-IR) with $\lambda=1064 \mathrm{~nm}$ and $f=10 \mathrm{~Hz}$, installed on a TORNADO-IDS aircraft. The aim of these tests was to obtain experimental data regarding the variations of the attenuation coefficient at $\lambda=1064 \mathrm{~nm}$ as a function of altitude. In order to cope with this task, it was first of all required to correctly plan the flight sorties and selecting the test points according to the aircraft envelope limitations (including the constrains imposed by laser eye-safety), to the range instrumentation mode of operation and to the CLDP-IR functional characteristics. Two flight sorties were executed in days with visibility in excess of $15 \mathrm{~km}$, including four dive maneuvers at $45^{\circ}, 35^{\circ}, 25^{\circ}$ and $15^{\circ}$ respectively. The dive profiles envelopes are described in the Table 22 .

Table 22. Flight profiles envelopes for propagation flight trials.

\begin{tabular}{|c|c|c|c|c|c|c|c|c||}
\hline \multirow{2}{*}{$\begin{array}{c}\text { Profile } \\
\text { Envelope }\end{array}$} & \multicolumn{2}{|c|}{$\mathbf{2 0}^{\circ}$ Dive } & \multicolumn{2}{|c|}{$\mathbf{3 0}^{\circ}$ Dive } & \multicolumn{2}{c||}{$\mathbf{4 0}^{\circ}$ Dive } & \multicolumn{2}{c||}{$\mathbf{5 0}^{\circ}$ Dive } \\
\cline { 2 - 9 } & Alt. & Dist. & Alt. & Dist. & Alt. & Dist. & Alt. & Dist. \\
\hline \hline Top & $14000 \mathrm{ft}$ & $12.5 \mathrm{~km}$ & $19000 \mathrm{ft}$ & $11.5 \mathrm{~km}$ & $20000 \mathrm{ft}$ & $9.5 \mathrm{~km}$ & $22000 \mathrm{ft}$ & $8.5 \mathrm{~km}$ \\
\hline Bottom & $6000 \mathrm{ft}$ & $5.5 \mathrm{~km}$ & $7000 \mathrm{ft}$ & $4 \mathrm{~km}$ & $8000 \mathrm{ft}$ & $4 \mathrm{~km}$ & $8000 \mathrm{ft}$ & $3.5 \mathrm{~km}$ \\
\hline \hline
\end{tabular}


When data could not be collected during the dives, straight and level passages were performed parallel to the target surface. In all cases, the CLDP-IR laser was manually activated by the WSO at the required altitudes and grazing angles. The CLDP-IR laser eye-safety envelope is shown in Fig. 14, with superimposed the dive profiles.

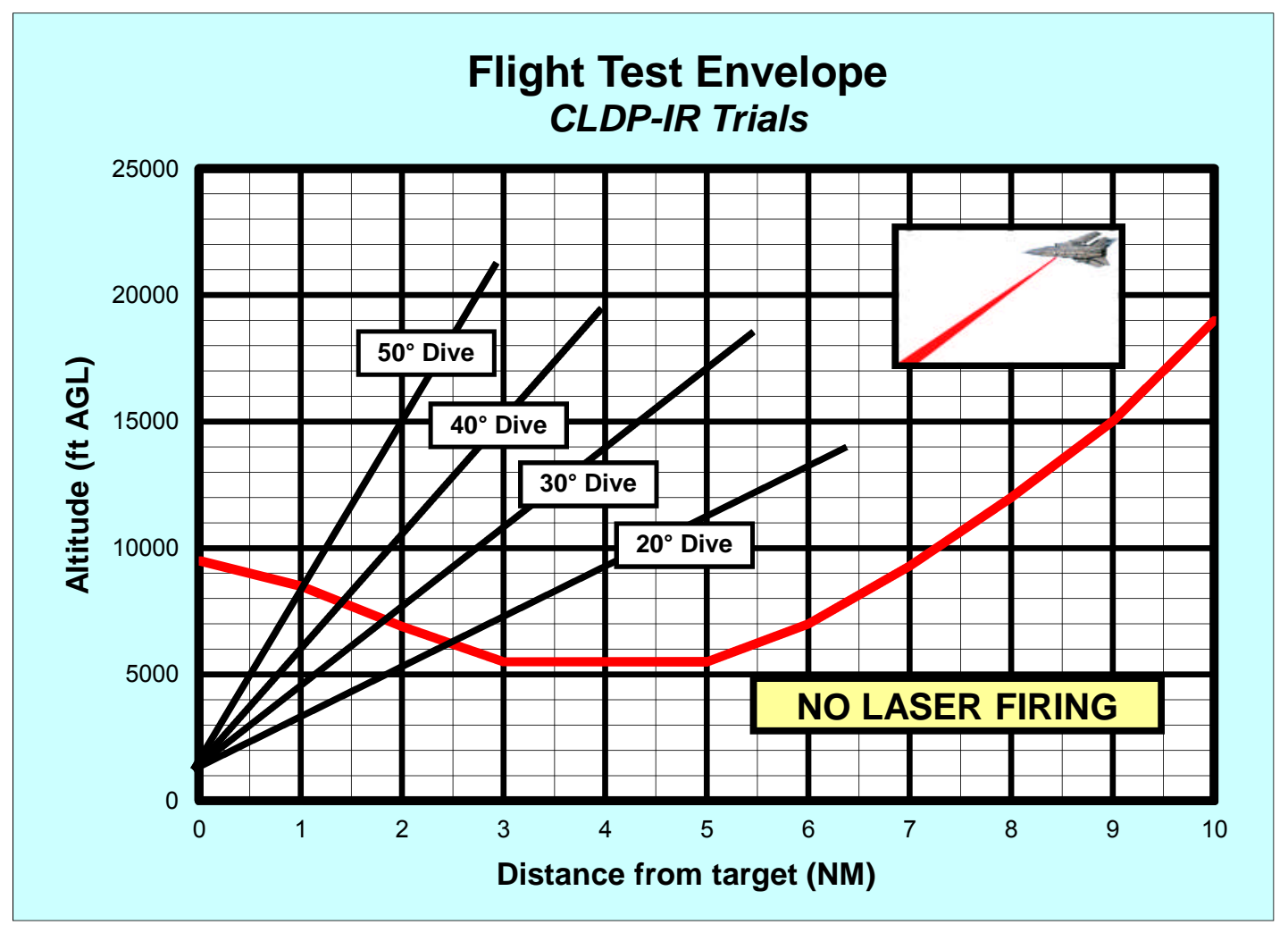

Fig. 14. CLDP-IR eye-safety envelope.

The flights were performed on two successive summer days. The meteorological data collected at the target location during the two sorties are reported in Table 23.

Table 23. Meteorological data relative to propagation flight trials.

\begin{tabular}{||c|c|c|c|c|c||}
\hline Sortie & $\begin{array}{c}\text { Visibility } \\
(\mathbf{k m})\end{array}$ & $\begin{array}{c}\text { Rel. Hum. } \\
(\boldsymbol{\%})\end{array}$ & $\begin{array}{c}\text { Temp. } \\
\left({ }^{\circ} \mathbf{C}\right)\end{array}$ & $\begin{array}{c}\text { Wind } \\
(\% / \mathbf{k t s})\end{array}$ & Cloud \\
\hline \hline $\mathbf{1}$ & $16 \mathrm{~km}$ & $57 \%$ & $35^{\circ} \mathrm{C}$ & $120 / 7$ & $0 / 8$ \\
\hline $\mathbf{2}$ & $18 \mathrm{~km}$ & $54 \%$ & $32^{\circ} \mathrm{C}$ & $0 / 0$ & $2 / 8$ \\
\hline
\end{tabular}

Following the planned flight profiles, experimental data collected during the two TORNADO-IDS sorties allowed to estimate the variations of the attenuation coefficient with altitude. Particularly, measuring transmittances for various aircraft grazing angles and altitudes (aircraft instrumented with Differential GPS and equipped with standard barometric/radar altimeters), the following results were found. The experimental data obtained and their linear fitting functions are shown in Fig 15, where $\gamma_{a t m}{ }^{H}$ is the attenuation coefficient of the slant-path, $\gamma_{a t m}$ is the attenuation coefficient at sea-level, and $H$ is the aircraft Mean Sea Level (MSL) altitude in thousands of $\mathrm{ft}$. Looking at the data 
trends, it is evident that, as the grazing angle $(\xi)$ becomes shallower, $\gamma_{a t m}{ }^{H}$ tends to decrease at a lower rate as the altitude increases. It must be considered that the linear fits relative to the various grazing angles are representative of the data trends only in the altitude intervals were the experimental data were collected. Furthermore, the experimental flight sorties were carried out only in clear weather with similar values of the relevant meteorological parameters measured on the ground (i.e., visibility, relative humidity and temperature). Therefore, it is possible that using these functions beyond the respective altitude intervals and in different weather conditions may not provide reliable predictions of the attenuation coefficient. In order to obtain accurate predictions of the attenuation coefficient variations with altitude, further trials have to be performed in appropriate meteorological and operational scenarios, including representative weather conditions and wider portions of the TORNADO-IDS/CLDP operational flight envelopes.

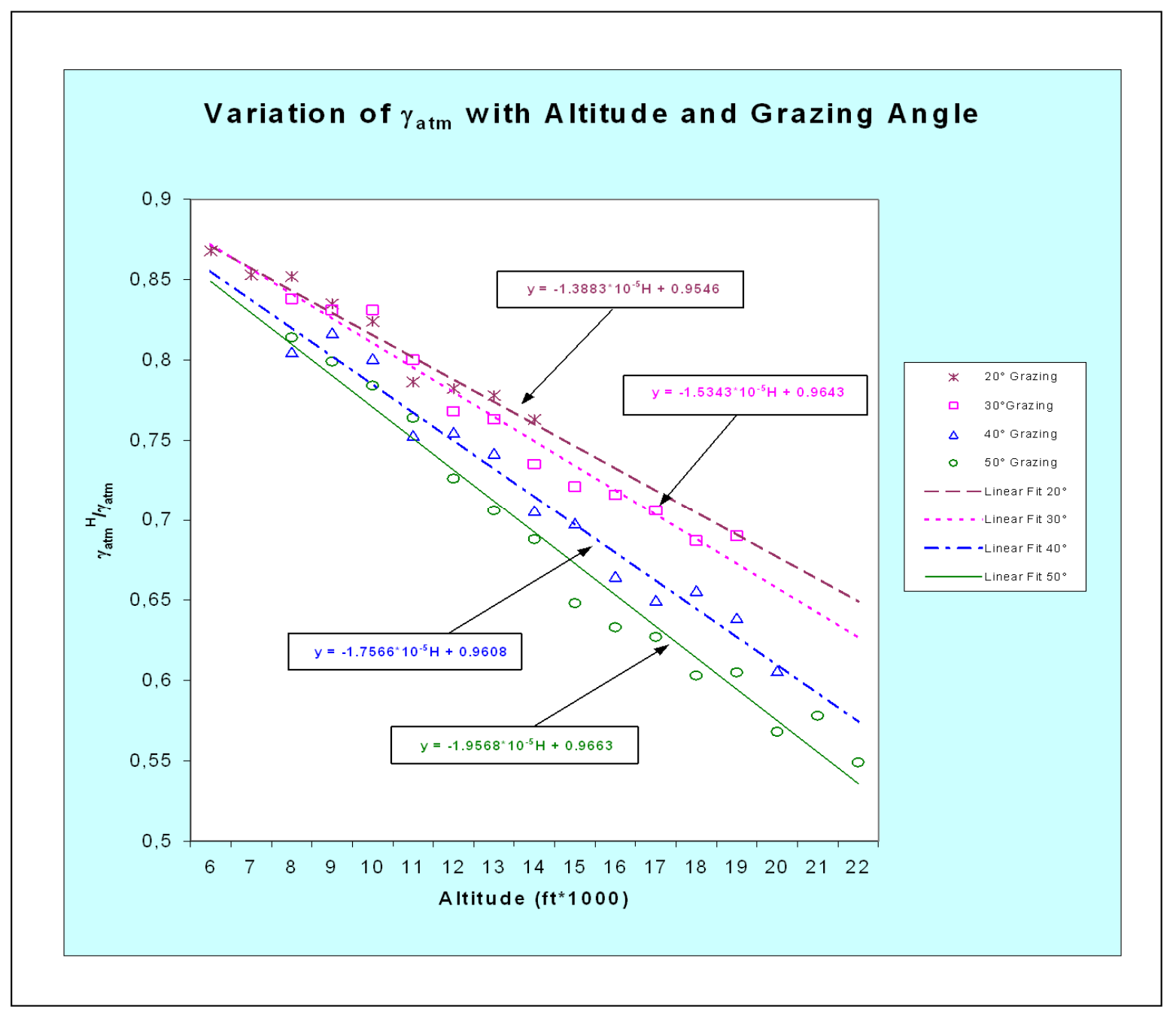

Figure 15. Ratio of the attenuation coefficient to its sea-level value for slant-paths with $20^{\circ}, 30^{\circ}, 40^{\circ}$ and $50^{\circ}$ grazing angles.

\section{CONCLUSIONS}

In this paper we have introduced some innovative methods for NIR laser propagation measurements that represent valid alternatives to traditional techniques and have potential applications to atmospheric sounding of a various gases and aerosol particles, including $\mathrm{CO}_{2}$ and particulate species. The proposed techniques and the associated mathematical models for extinction data analysis and particle $/ \mathrm{CO}_{2}$ retrieval have been defined. Some ground and flight test activities were performed in order to validate the proposed techniques and to assess/improve the mathematical models used for 
atmospheric extinction predictions. Particularly, both ground and flight test activities results are presented performed with laser systems operating in the NIR at $\lambda=1064 \mathrm{~nm}$ and $\lambda=1550 \mathrm{~nm}$. This includes actual ground trials with high/low PRF laser systems, and flight trials performed with a pulsed airborne laser system installed on a TORNADO aircraft. During these test activities some measurements were performed of horizontal and oblique/vertical path atmospheric transmission up to altitudes of $22,000 \mathrm{ft}$ AGL, in a variety of atmospheric conditions. The results of these test activities indicate that the techniques and models are valid and can be used for the purpose of atmospheric sounding and carbon dioxide column density measurement. Further ground and flight test activities are required in order to build a Laser Propagation Database (LPDB) that will improve the quality of our predictions and provide additional information about the variation of the relevant atmospheric parameters over extended altitudes and in a wider range of experimental conditions. Additionally, using the LPDP, the techniques developed for $\mathrm{CO}_{2}$ column density retrieval will be tested, with emphasis on aircraft related emissions at airports and other high air-traffic density environments.

\section{REFERENCES}

[1] Weichel H., "Laser Beam Propagation in the Atmosphere," SPIE Optical Engineering Press. Second Printing (1990).

[2] Hudson R.D., [Infrared Systems Engineering]. Wiley \& Sons (1969).

[3] Elder T. and Strong J., "The Infrared Transmission of Atmospheric Windows". J. Franklin Institute 255 - 189 (1953).

[4] Langer R.M., Signal Corps Report n DA-36-039-SC-72351 (1957).

[5] Middleton W.E.K., "Vision Through the Atmosphere," University of Toronto Press (1952).

[6] Middleton W.E.K., "Vision Through the Atmosphere," Handbuch der Physik 48. Geophysics 2. Springer, Berlin (1957).

[7] Kneizys F.X., Shuttle E.P., Abreau L.W., Chetwynd J.H., Anderson G.P., Gallery W.O., Selby J.E.A., and Clough S.A., "Users Guide to LOWTRAN 7," Air Force Geophysical Laboratory Report AFGL-TR-88-0177. Hansom AFB (1988).

[8] Holst G.C., [Electro-Optical Imaging System Performance], SPIE Optical Engineering Press. Bellingham, Washington USA (1995).

[9] Gebhardt F.G., "High Power Laser Propagation,” Applied Optics - Vol. 15, p. 1479 (1976).

[10] Rodgers C.D., "Inverse Methods for Atmospheric Sounding: Theory and Practice," Atmos. Oceanic Planet. Phys. - Vol. 2 (p. 238). World Science. River Edge, NJ (2000).

[11] Veselovskii I., Kolgotin A., Griaznov V., Müller D., Franke K., and Whiteman D., "Inversion of multiwavelength Raman lidar data for retrieval of bimodal aerosol size distribution". Appl. Optics - Vol. 43, pp. 1180-1195 (2004).

[12] Müller D., Wagner F., Wandinger U., Ansmann A., Wendisch M., Althausen D., and Hoyningen-Huene von W., "Microphysical particle parameters from extinction and backscatter lidar data by inversion with regularization: Experiment". Appl. Optics - Vol. 39, pp. 1879-1892 (2000).

[13] Abshire J.B., Riris H., Allan G.R., Weaver C.J., MAO J., Sun X., Hasselbrack W.E., Kawar R. and Biraud S., "Pulsed airborne lidar measurements of atmospheric $\mathrm{CO}_{2}$ column absorption". Tellus Journal - International Meteorological Institute in Stockholm. 2010.

[14] Krainak, M.A, Andrews, A. E., Allan, G. R., Burris, J. F., Riris, H. and co-authors, "Measurements of atmospheric $\mathrm{CO}_{2}$ over a horizontal path using a tunable-diode-laser and erbium-fiber-amplifier at $1572 \mathrm{~nm}$," Proceedings of the Conference on Lasers and Electro-Optics/Quantum Electronics and Laser Science. Technical Digest, Optical Society of America, paper CTuX4, 878-881, ISBN: 1-55752-748-2 (2003).

[15] Riris, H., Abshire, J., Allan, G., Burris, J., Chen, J. and co-authors, "A laser sounder for measuring atmospheric trace gases from space," Proc. SPIE 6750, 67500U, doi:10.1117/12.737607 (2007).

[16] Allan G. R., Riris, H., Abshire J. B., Sun X., Wilson E. and co-authors, "Laser sounder for active remote sensing measurements of $\mathrm{CO}_{2}$ concentrations," Proceedings of the 2008 IEEE Aerospace Conference. IEEE, Big Sky, MT. 1534-1540, doi:10.1109/AERO.2008.4526387 (2008).

[17] Amediek, A., Fix, A. Ehret, G. Caron, J. and Durand, Y., "Airborne lidar reflectance measurements at 1.57 um in support of the A-SCOPE mission for atmospheric $\mathrm{CO}_{2}$," Atmos. Meas. Tech. Discuss. 2, 1487-1536 (2009). 